\title{
An intercomparison between the GSWM, UARS, and ground based radar observations: a case-study in January 1993
}

\author{
${ }^{1}$ National Center for Atmospheric Research, Boulder, CO, USA \\ ${ }^{2}$ University of Saskatchewan, Saskatoon, Canada \\ ${ }^{3}$ University of Adelaide, Adelaide, Australia \\ ${ }^{4}$ University of Michigan, Ann Arbor, MI, USA \\ ${ }^{5}$ York University, Toronto, Canada \\ ${ }^{6}$ University of Illinois, Urbana, IL, USA \\ ${ }^{7}$ University of New Hampshire, Durham, NH, USA \\ ${ }^{8}$ Institut für Atmosphärenphysik, Kühlungsborn, Germany \\ ${ }^{9}$ Leipzig University, Collm, Germany \\ ${ }^{10}$ Australian Antarctic Division, Kingston, Australia \\ ${ }^{11}$ Kyoto University, Kyoto, Japan \\ 12 Institute of Experimental Meteorology, Obninsk, Russia \\ ${ }_{13}$ Massachusetts Institute of Technology, Westford, MA, USA \\ 14 The University College of Wales, Aberystwyth, UK \\ ${ }^{15}$ Arecibo Observatory, Arecibo, Puerto Rico
}

S. E. Palo ${ }^{1}$, M. E. Hagan ${ }^{1}$, C. E. Meek ${ }^{2}$, R. A. Vincent ${ }^{3}$, M. D. Burrage ${ }^{4}$, C. McLandress ${ }^{5}$, S. J. Franke , $^{6}$ W. E. Ward ${ }^{5}$, R. R. Clark $^{7}$, P. Hoffmann ${ }^{8}$, R. Johnson ${ }^{4}$, D. Kürschner ${ }^{9}$, A. H. Manson ${ }^{2}$, D. Murphy ${ }^{10}$, T. Nakamura ${ }^{11}$, Yu. I. Portnyagin ${ }^{12}$, J. E. Salah ${ }^{13}$, R. Schminder ${ }^{9}$, W. Singer ${ }^{8}$, T. Tsuda ${ }^{11}$, T. S. Virdi ${ }^{14}$, Q. Zhou ${ }^{15}$

Received: 14 October 1996 / Revised: 20 February 1997 / Accepted: 24 February 1997

\begin{abstract}
The Global-Scale Wave Model (GSWM) is a steady-state two-dimensional linearized model capable of simulating the solar tides and planetary waves. In an effort to understand the capabilities and limitations of the GSWM throughout the upper mesosphere and thermosphere a comparative analysis with observational data is presented. A majority of the observational data used in this study was collected during the World Day campaign which ran from 20 January to 30 January 1993. During this campaign data from 18 ground-based observational sites across the globe and two instruments located on the UARS spacecraft were analyzed. Comparisons of these data with the simulations from the GSWM indicate that the GSWM results are in reasonable agreement with the observations. However, there are a number of cases where the agreement is not particularly good. One such instance is for the semidiurnal tide in the northern hemisphere, where the GSWM estimates may exceed observations by $50 \%$. Through a number of numerical simulations, it appears that this discrepancy may be due to the eddy diffusivity profiles used by the GSWM. Other differences relating to the diurnal tide and the quasi-two-day wave are presented and discussed. Additionally, a discussion on the biases
\end{abstract}

Correspondence to: S. E. Palo and aliasing difficulties which may arise in the observational data is also presented.

\section{Introduction}

During the 10 days from 20 January to 30 January, 1993, a coordinated ground- and spaced-based observational campaign of the mesosphere and lower thermosphere was conducted. This campaign is the ninth in a series of lower-thermosphere coupling studies (LTCS), and coincides with the fifth MLTCS campaign, designed to study the dynamics of the atmosphere between 80 and $130 \mathrm{~km}$ (Forbes, 1990) and is the longest duration LTCS/MLTCS campaign to date. During this campaign numerous ground and satellite instruments, which provide estimates of the neutral horizontal wind field in the mesosphere and lower thermosphere, were operational. The data collected during this campaign period were analyzed and compared with the GlobalScale Wave Model (GSWM) (Hagan et al., 1993, 1995), climatalogical predictions of the semidiurnal and diurnaltides, and the quasi-two-day wave. By comparing the observational data with the GSWM simulations we have been able to evaluate the GSWM predictions both qualitatively and quantitatively in an effort better to 
understand the dynamical structure of the upper mesosphere and lower thermosphere. This is the first detailed comparison of the GSWM semidiurnal tidal predictions with observational data. However, there have been a number of comparisons of the GSWM predictions of the diurnal tide with observational climatologies (Hanga et al., 1994; Burrage et al., 1995; McLandress et al., 1996)

For the purpose of this study, data from 18 groundbased radar systems have been analyzed. These consist of data collected from low-frequency, medium-frequency, meteor, and incoherent-scatter radars located around the globe. Figure 1 is a Mercator projection of the globe between $70^{\circ} \mathrm{S}$ and $70^{\circ} \mathrm{N}$ with the locations of the ground-based radar systems indicated by filled circles. These 18 sites consist of the same 15 sites described in the analysis by Deng et al., (1996) in addition to the Sondrestrom $\left(67^{\circ} \mathrm{N}, 51^{\circ} \mathrm{W}\right)$ and EISCAT $\left(69.0^{\circ} \mathrm{N}, 19.2^{\circ} \mathrm{E}\right)$ incoherent-scatter radar systems and the Obninsk $\left(54^{\circ} \mathrm{N}, 38^{\circ} \mathrm{E}\right)$ meteor radar system. Due to the paucity of observational facilities in the equatorial region and the southern hemisphere (see Fig. 1), it is difficult to evaluate the model performance on a global scale without utilizing an assimilative technique (Forbes and Salah, 1991) or satellite observations. Therefore, in addition to the ground-based data, data from the highresolution Doppler imager (HRDI) (Hays et al., 1993) and the wind imaging interferometer (WINDII) (Shepherd et al., 1993) which are on the Upper-Atmosphere Research Satellite (UARS) (Reber et al., 1993) have been analyzed. The shaded region in Fig. 1 indicates the nominal region where data are available from the HRDI and WINDII instruments. Due to the satellite orbital geometry and position of the HRDI and WINDII instruments on the satellite only the region from $70^{\circ} \mathrm{S}$ to $40^{\circ} \mathrm{N}$ was observable during the 20-30 January timeinterval. However, in the tidal analysis of the HRDI and WINDII data, it was sometimes necessary to analyze data from other months (December and February) or other years (January 1992 and 1994) to reduce the systematic aliasing effect due to the slow orbital precession of the satellite and random errors associated with the data to acceptable levels. Due to the inclusion of these data it is possible, in some cases, to report results as far north as $58^{\circ}$. Now, because we are interested in the climatalogical structure of the tides, the inclusion of data from other years and other months will not be detrimental to this study. In fact, without these additional data, many of the tidal fields presented in this study could not be extracted from the data.

The focus of this paper is to assess how accurately the GSWM describes the salient features of the mesospheric and lower-thermospheric wind field during January. In this comparison it will be obvious that there are some significant differences between the ground-based and satellite-based estimates of mean, tidal, and planetary wave parameters. Although not fully resolved, this issue has been addressed at a number of workshops (Geller, 1994), and in recent papers by Khattatov et al., (1996) and Burrage et al. (1996). Therefore, in cases where the ground- and satellite-based measurements disagree we will provide our best estimate of the model performance based upon current knowledge of possible instrumental biases and refer the reader to the aforementioned references for additional information.

The campaign period during January 1993 was shortly following the December solstice and was characterized by low geomagnetic activity throughout the 10

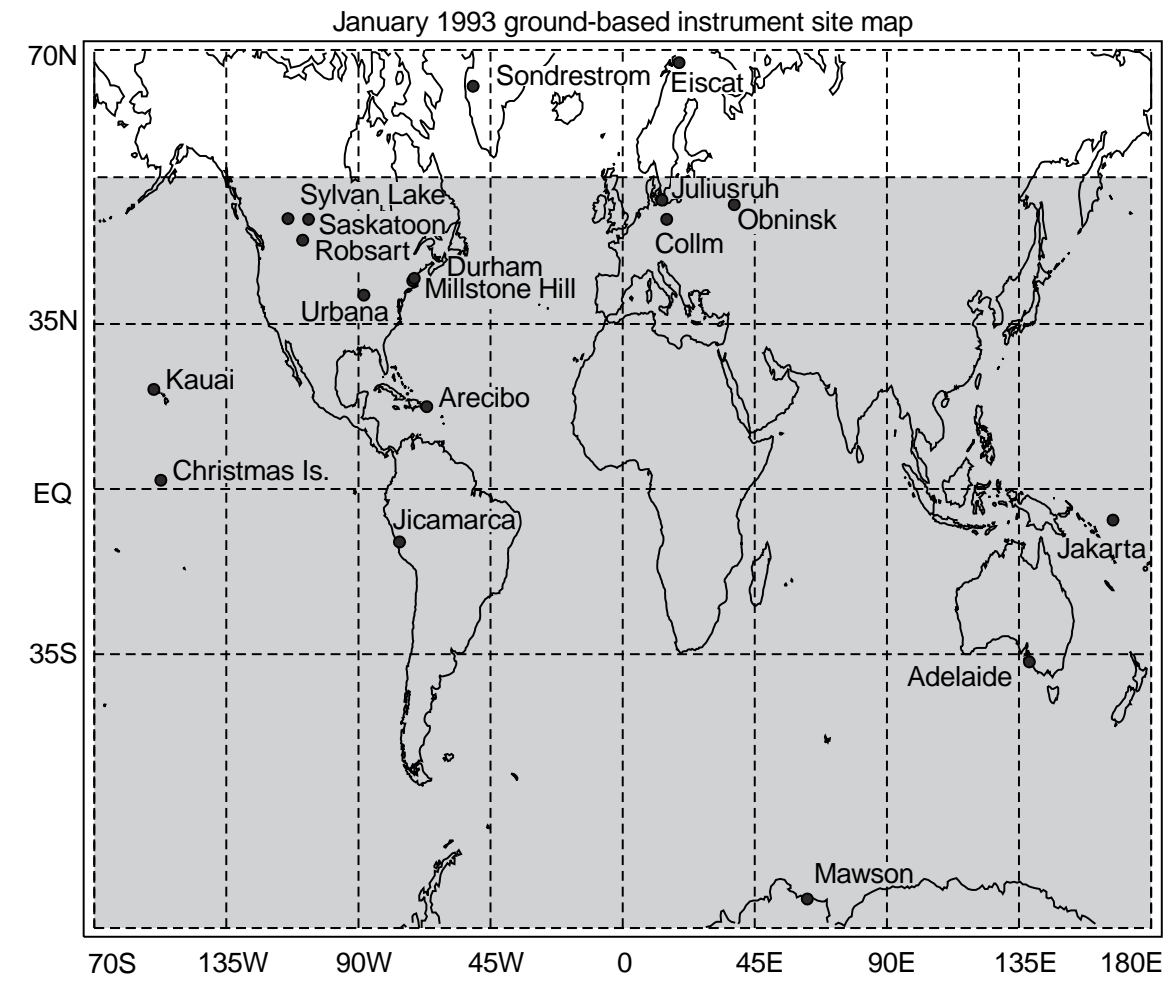

Fig. 1. A map indicating the geographic location of the ground-based instruments which provided data for this study. The shaded region indicates the nominal latitude range where UARS HRDI and WINDII data were available 
days. The only exception was for $12 \mathrm{~h}$ on 25 January where the $\mathrm{K}_{\mathrm{p}}$ index exceeded 4 [see Fig. 1 in Deng et al. (1996)]. The zonal mean structure of the zonal wind field near the solstices consists of two jets in the upper stratosphere and mesosphere near mid-latitudes in each hemisphere, which reverse near the lower-thermosphere. Around the December solstice the northern (southern) hemisphere upper-stratospheric jet is eastward (westward) while the lower-thermospheric jet is westward (eastward) (Rees et al., 1990) The amplitude structure of the diurnal tide during this period is largely latitudinally symmetric with an expected maximum near $20^{\circ}$ in the lower thermosphere (Hagan et al., 1995). However, there is some observable difference between the latitudinal structure of the diurnal tide in the two hemispheres. Near the solstices the diurnal tide is at a semiannual minimum while the semidiurnal tide is at a semiannual maximum. In contrast to the diurnal tide, the semidiurnal tide contributes to the wind field poleward of $30^{\circ}$ and maximizes near $120 \mathrm{~km}$ in the lower thermosphere. Also present, shortly following the solstices, is the quasi-two-day wave (Hangan et al., 1993; Harris, 1994; Palo and Avery, 1996; Meek et al., 1996). Previous observations of the quasi-two-day wave during January indicate that it can dominate the meridional flow in the southern hemisphere with amplitudes in excess of $50 \mathrm{~m} \mathrm{~s}^{-1}$. Estimated power spectra for a subset of data from the ground-based radar stations are presented in Deng et al. (1996) and indicate the presence of significant wave activity at periods of $12 \mathrm{~h}$ (semidiurnal tide), $24 \mathrm{~h}$ (diurnal tide) and $48 \mathrm{~h}$ (quasi-two-day wave) during the campaign period. However, the relative strengths of these components change with both altitude and latitude.

\subsection{The global-scale wave model}

Hagan et al. $(1993,1995)$ introduced the GSHM: a twodimensional, linearized, steady-state numerical tidal and planetary wave model extending from the ground to the thermosphere. The hierarchical structure of the GSWM is based upon that of Forbes (1982). However, the specifications of the background atmosphere, tidal forcing, and dissipation parameterizations in the GSWM represent significant extensions and improvements to the older tidal model. In addition, the GSWM is the first simple model to include a scheme to account for the effects of gravity wave drag on the diurnal tide. This extension combined with the aforementioned fine tuning has resulted in the calculation of more realistic migrating solar diurnal and semidiurnal tides from the ground into the MLT and the first numerical prediction of interhemispheric seasonal variability of the diurnal harmonic (Hagan et al., 1995; Burrage et al., 1995.

Tidal and planetary wave dissipation occurs throughout the atmosphere and may be attributable to ion drag, molecular and eddy viscosity and conductivity, and radiative damping. GSWM molecular conductivity and viscosity as well as ion drag and Newtonian cooling parameterizations of radiative damping are discussed by
Hagan et al. (1993). The GSWM employs a series of eddy diffusion coefficients, $K_{z z}$, and explicitly calculates the divergences of the associated heat and momentum fluxes in the model (Forbes, 1982). The $K_{z z}$ account for the effects of turbulence generated by gravity waves as they become unstable and finally break in the MLT. GSWM $K_{z z}$ are based on the climatology calculated by Garcia and Solomon (1985) and are discussed in detail by Hagan et al., (1995). The GSWM also includes an effective Rayleigh friction coefficient after Miyahara et al. (1991) to account for the suppression of the diurnal tide by gravity wave drag (Hagan et al., 1995) This parameterization, heretofore neglected in linear tidal models, is used in the GSWM diurnal calculations exclusively. For more information on the GSWM the reader is directed to Hagan et al. $(1993,1995)$.

\section{Data processing}

In this study emphasis was placed upon consistent processing of all the ground-based data and a significant effort was made to ensure the integrity of these data. To accomplish this task, all the ground-based data were analyzed at multiple institutions independently and subsequently cross-validated. With all such data processed in a consistent manner one can make a reasonable comparison of the results and estimated errors between each observational site. The technique used to analyze the data presented in this paper may be different from the techniques typically used to estimate the tidal and planetary waves at each site. One such case is the Jakarta meteor radar (Tsuda et al., 1987; Nakamura et al., 1996).

All of the ground-based data presented here were analyzed using a simple linear least-squares fitting algorithm. The model which was fitted to the data included a mean, in addition to 12,24 , and 48-h sinusoids. In some cases where there were large periodic gaps in the data (e.g., Millstone Hill, Arecibo, and Jicamarca) the model which was fitted to the data did not include a 24-h component. This method of analyzing the data is not uncommon (Salah et al., 1991) where observations are not available for $24 \mathrm{~h}$ each day. The reason for this approach is that the diurnal tide aliases with the mean and the semidiurnal tide, and if the 24-h component is included in the fit the model used for the fit is rank deficient, resulting in numerical difficulties with the fit. This aliasing problem will be discussed further in the next section.

In addition to the amplitudes and phases of the specified harmonic components, the least-squares fitting routine also returns estimates of the $1-\sigma$ confidence intervals. These $1-\sigma$ confidence intervals are shown on all of our plots and are computed using the method described in Palo and Avery (1993). To compute these confidence intervals it is assumed that the residual fitting error can be described as Gaussian-white-noise, and then a Student's T-test is used to estimate the confidence interval. While the Gaussian-white-noise assumption may not always be correct, it does provide a reasonable 
basis to estimate the error associated with the estimated amplitudes and phases.

When comparing observations made from different types of instruments with a model it is important to understand the limitations and difficulties which are inherent to each technique in addition to the limitations of the model. In particular, for this study, we have employed data from ground-based facilities which include medium-frequency, high-frequency, meteor, and incoherent-scatter radars, and satellite-borne optical instruments. Rather than discuss each technique in detail we will highlight only the issues pertinent to this study, and refer the reader to references on the specified technique for more details (Evans, 1978; Röttger et al., 1983; Briggs, 1984; Roper, 1984; Hays et al., 1993; Shepherd et al., 1993; Virdi and Williams, 1993; Williams et al., 1994; Tsuda, 1995).

\subsection{Aliasing}

Fundamental to Fourier analysis are the concepts of sampling and aliasing. In effect, any signal which is sampled in one domain (time or frequency) will be periodic in the other (frequency or time). If the sampled signal is bandlimited and uniformly sampled at a sufficient rate, then the original continuous signal can be reconstructed from these samples and no information is lost. However, if the original signal is not uniformly sampled at a sufficient rate then the original signal cannot be fully reconstructed from its samples. In this case the original signal is said to be aliased. If the data are uniformly sampled then the relationship between sampling and aliasing is fully described by the ShannonWhittaker sampling theorem (Roberts and Mullis, 1987). Unfortunately, as is often the case in remote sensing, the data is not uniformly sampled and the situation becomes more complicated. However, while an analytic solution cannot be computed for the nonuniformly sampled cases, these cases can be evaluated numerically to provide some insight into possible aliasing problems which may arise.

One method for evaluating the aliasing which will occur from nonuniform sampling is to compute an aliasing mask in the time domain and Fourier transform this aliasing mask to determine its effect in the frequency domain. The aliasing mask is simply computed by creating a dense uniform grid which contains all of the sampling times. Then if a grid point coincides with a sample point a 1 is placed at this position in the series, otherwise a zero placed there. Notice that multiplying the sampling mask by the original time-series, sampled at the dense uniform rate, will result in the nonuniformly sampled time-series. Therefore, the Fourier transform of the nonuniformly sampled time-series, must be equal to the Fourier transform of the original time-series convolved with the Fourier-transformed aliasing mask.

Figure 2 shows the amplitude spectrum of five aliasing masks. These curves were generated by computing the magnitude of the Fourier-transformed aliasing masks, where the Fourier transform was zero

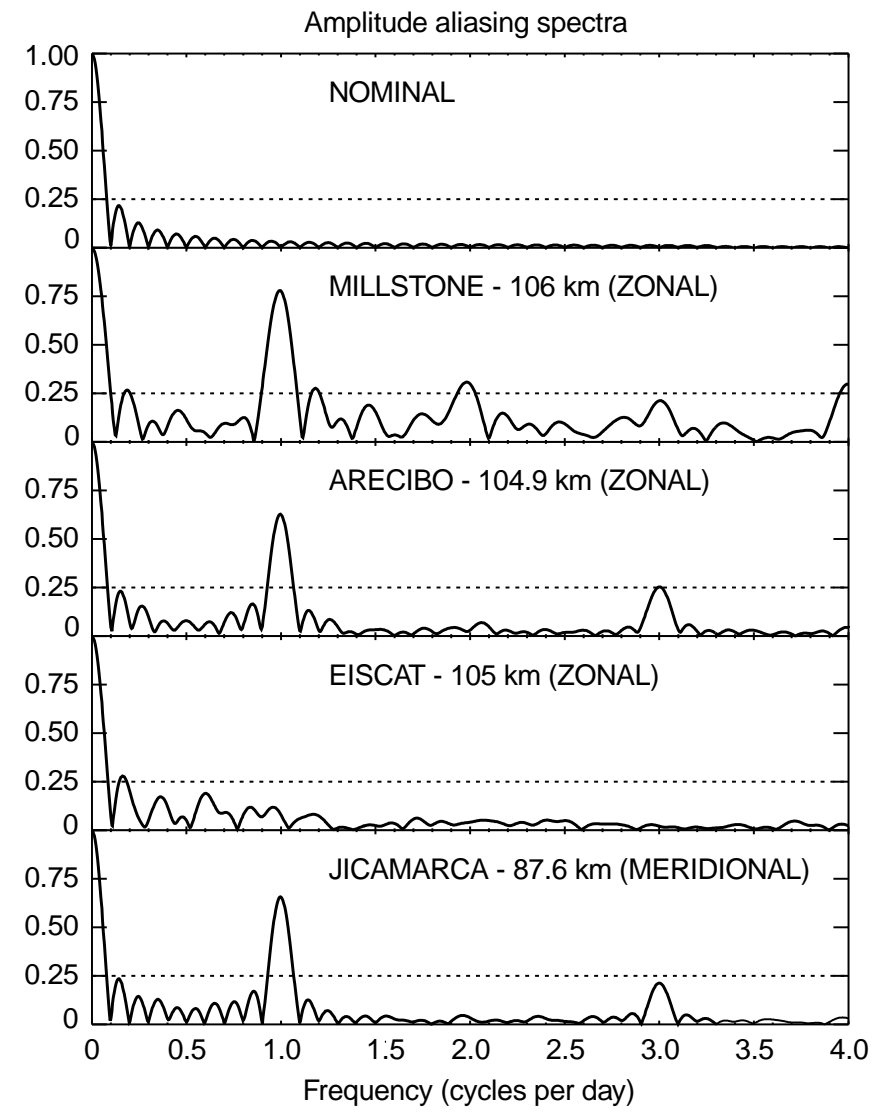

Fig. 2. An example of the aliasing spectrum which results from nonuniformly sampling the observed time- series. The aliasing spectra are shown for the nominal case when the time-series is uniformly sampled (top), the Millstone Hill zonal winds at $106 \mathrm{~km}$ (second from top), the Arecibo zonal winds at $104.9 \mathrm{~km}$ (third from top), the EISCAT zonal winds at $105 \mathrm{~km}$ (fourth from top), and the Jicamarca meridional winds at $87.5 \mathrm{~km}$, respectively

padded to provide additional points in the frequency domain. The top plot shows the nominal aliasing mask for a 10-day interval of observations with a measurement every hour. Notice, this is a basic $\sin (x) / x$ or $\operatorname{sinc}(x)$ kernel as one would expect. The four curves below the nominal case are for the Millstone Hill data at $106 \mathrm{~km}$, the Arecibo data at $104.9 \mathrm{~km}$, the EISCAT data at $105 \mathrm{~km}$, and the Jicamarca data at $87.5 \mathrm{~km}$. The dashed line on these plots indicates an amplitude contribution equal to $25 \%$ of that from the mainlobe. Clearly evident in this figure is a large sidelobe at a frequency of 1 cpd (cycles per day) for the Millstone Hill, Arecibo, and Jicamarca results. Also present are smaller peaks at frequencies of 2,3 , and $4 \mathrm{cpd}$. These peaks result from the lack of nighttime data at these altitudes and will clearly result in the mixing of power from multiple-frequency bands. As the aliasing spectrum is convolved with the original spectrum, when analyzing these data power near a period of $24 \mathrm{~h}$ will be aliasing into the mean, power near the mean and $12 \mathrm{~h}$ will be aliasing into the diurnal tide and power near $24 \mathrm{~h}$ and $8 \mathrm{~h}$ will be aliased into the semidiurnal tide. All of this mixing would result from the sidelobe at a frequency of $1 \mathrm{cpd}$. However, the full effect of this 
aliasing cannot simply be determined from the magnitude of the aliasing spectrum, because both the aliasing and the original data spectra are complex, and the phase of each will play a major role in the overall aliasing effect. It should be noted that this is an effect that will be encountered by any instrument which systematically lacks measurements during the sametime-period each day; this has been previously recognized by the incoherent-scatter radar community.

In addition to the ground-based observations, the observations from the HRDI and WINDII instruments located on UARS also have aliasing difficulties. These difficulties arise due to the slow orbital precession rate of the UARS satellite ( $20 \mathrm{~min}$ of local time per day). At the equator, the ascending and descending nodes of the satellite orbit are separated by slightly less than $12 \mathrm{~h}$ in local time, but as one moves towards the poles this separation changes. As a result of this sampling, it is difficult to extract the semidiurnal and diurnal tides using standard processing methods for periods less than a few months, and therefore data from multiple months and multiple years is typically used in the estimation of these parameters (Hays et al., 1994; Burrage et al., 1995; McLandress et al., 1996). In the case of the quasi-twoday wave the aliasing difficulties are reduced because there are no significant oscillations present at the frequency/wave-number coordinates for the quasi-twoday wave aliases (Wu et al., 1993). Therefore it is possible to extract the amplitude and phase structure of the quasi-two-day wave on a daily basis (Wu et al., 1993; Ward et al., 1996).

A second type of aliasing which is common in ground-based observations is wave-number aliasing. This aliasing is due to the fact that a ground-based observational station observes at one fixed geographic location. As a result of the observational geometry, no wave-number information can be retrieved, and in essence all of the wave-numbers are aliased. Without this wave-number information the migrating diurnal and semidiurnal tides as well as the quasi-two-day wave cannot be extracted from these data, but rather these components must be inferred from the data. This inference is made simply by assuming that the observed 12-h component is the migrating semidiurnal tide, the observed 24-h component is the migrating diurnal tide, and the observed 48-h component, or thereabouts, is the quasi-two-day wave. However, problems will arise if there are waves present at the specified frequencies with wave-numbers which are not associated with the tides and quasi-two-day wave. Two such problems can arise in the tropical and subtropical regions when analyzing the diurnal tide. One such difficulty is due to the presence of inerto-gravity waves. Equatorward of $30^{\circ}$ latitude these waves can exist with periods in excess of $24 \mathrm{~h}$ and may contribute significant energy to the wave spectrum. An additional difficulty may arise due to the nonmigrating diurnal tide; this is the global-scale disturbance with a period of $24 \mathrm{~h}$ which does not propagate with the apparent motion of the sun (Williams and Avery, 1996). Recent work by Hagan et al. (1997a, b), indicates that the nonmigrating diurnal tide can play a significant role in the structure of the diurnal tide observed in the middle atmosphere at low latitudes.

The effects of wave-number aliasing on a specified wave component is variable and depends on the amplitude and phase structure of all the waves involved. To observe this feature, assume $N$ waves are present around a given latitude circle at some constant altitude, each with a temporal radian frequency of $\omega$, a distinct zonal wavenumber $s_{n}$, an amplitude $A_{n}$, and a phase offset $\phi_{n}$. Then the time and frequency structure around this latitude circle is

$y(t, x)=\sum_{n=0}^{N-1} A_{n} \cos \left(\omega t+s_{n} x+\phi_{n}\right)$

where $t$ is time and $x=\frac{2 \pi}{360} \lambda$ is a normalized radian distance. Now, Eq. 1 can be manipulated using simple trigonometric identities to yield

$$
\begin{aligned}
y(t, x)= & B(x) \cos (\omega t+\zeta(x)), \\
B(x)= & \left(\left(\sum_{n=0}^{N-1} A_{n} \cos \left(s_{n} x+\phi_{n}\right)\right)^{2}\right. \\
& \left.+\left(\sum_{n=0}^{N-1} A_{n} \sin \left(s_{n} x+\phi_{n}\right)\right)^{2}\right)^{1 / 2}, \\
\zeta(x)= & \tan ^{-1}\left(\frac{\sum_{n=0}^{N-1} A_{n} \sin \left(s_{n} x+\phi_{n}\right)}{\sum_{n=0}^{N-1} A_{n} \cos \left(s_{n} x+\phi_{n}\right)}\right) .
\end{aligned}
$$

In this modified form, it is obvious that a ground-based observing station located at a longitude $\lambda$, on this latitude circle, will infer an amplitude and phase of $B(x)$ and $\zeta(x)$ for the temporal frequency $\omega$. Additionally, it is clear from Eqs. 2-4, that the effect of this aliasing is dependent upon the location of the observing station and the structure of all of the wave components involved.

\subsection{Overestimation of amplitudes}

In addition to the aliasing difficulties, which may develop in analyzing observational data, it is also possible that the amplitudes of any estimated harmonic component are overestimated. This effect is stochastic and will vary depending upon the geographic location of the instrument, the time of year, and the duration of the observations. To illustrate this effect more clearly, Fig. 3 has been included.

Figure 3 shows the presence of two narrowband frequency components at frequencies of $\omega_{1}$ and $\omega_{2}$ in different noise environments. In Fig. 3a the harmonic components, each with a power of $A$, are shown in the presence of white noise with a noise variance of $\sigma^{2}$. Notice that while the power associated with each narrowband signal is $A$, the total power at each of the 


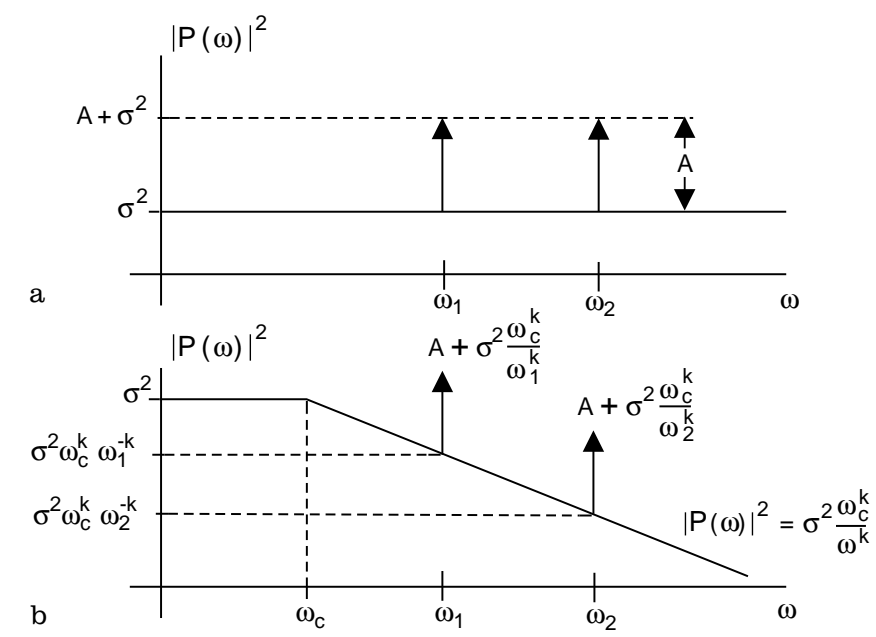

Fig. 3a, b. An example of the overestimation of tidal amplitudes which may result due to the underlying geophysical noise floor. The results are shown for a white noise and $\mathbf{b}$ colored noise

frequencies, $\omega_{1}$ and $\omega_{2}$, is $A+\sigma^{2}$. Now, the result of a least-squares fit to the harmonic component $\omega_{1}$ or $\omega_{2}$ would be $\sqrt{A+\beta \sigma^{2}}$, where $\beta$ is the bandwidth of the subspace defined by the least-squares fit. Clearly, as $\sigma^{2}>0$ and $\beta>0$, the estimate of the amplitude of the harmonic component will always be an overestimation of the true amplitude. The amount by which the fit overestimates the true amplitude will depend upon the noise variance $\left(\sigma^{2}\right)$ and the subspace bandwidth $(\beta)$.

If the noise is not white, then the overestimation problem becomes frequency dependent. Figure $3 \mathrm{~b}$ shows the presence of two frequency components in a colorednoise environment. In this case the noise is colored red and designed to replicate the expected noise spectrum observed in the middle atmosphere. Now, the result of a least-squares fit to the harmonic component $\omega_{1}$ would be $\sqrt{A+\beta \sigma^{2}\left(\omega_{1}\right)}$, where $\sigma^{2}\left(\omega_{1}\right)$ is the noise variance at $\omega_{1}$. Assuming the noise decays logarithmically from $\sigma^{2}$, at some cutoff frequency $\omega_{c}$, then $\sigma^{2}\left(\omega_{1}\right)=\sigma^{2} \omega_{c}^{k} \omega_{1}^{-k}$.

When the data are uniformly sampled, then the subspace bandwidth is related to the duration of the observation period. Approximating the bandwidth as the frequency span between the first two nulls of the sinc kernel, which results from a finite observation period, then $\beta=\frac{2}{T}$, where $T$ is the duration of the observation interval. Using observations taken at Christmas Island with a medium-frequency radar (Vincent and Lesicar, 1991) an estimate of this overestimation error can be made. Using an observation interval of 10 days the subspace bandwidth is $\beta=0.2$ days $^{-1}$. Table 1 indicates the expected overestimation error assuming no narrowband signal is present at each of the listed frequencies, which is the worst-case scenario. These results indicate that an overestimation error between 2 and $7 \mathrm{~m} \mathrm{~s}^{-1}$ is not unrealistic for the tides and the quasi-two-day wave. It should be noted that these values are computed from a rough estimate of the average noise value and that because the noise is a stochastic process which depends upon season and geographic location, these results must be interpreted simply as a guideline and should be
Table 1. An estimate of the amplitude offset due to the presence of geophysical noise. The bandwidth is consistent with an observing interval of 10 days and the noise power is estimated from Vincent and Lesicar (1991)

\begin{tabular}{llll}
\hline $\begin{array}{l}\text { period } \\
\mathrm{h}\end{array}$ & $\begin{array}{l}\text { noise power } \\
\mathrm{m}^{2} \mathrm{~s}^{-2} \mathrm{~Hz}^{-1}\end{array}$ & $\begin{array}{l}\text { band width } \\
\mathrm{Hz}\end{array}$ & $\begin{array}{l}\sqrt{\beta \sigma^{2}(\omega)} \\
\mathrm{m} \mathrm{s}^{-1}\end{array}$ \\
\hline 48 & $2 \times 10^{7}$ & $2.314 \times 10^{-6}$ & 6.8 \\
24 & $1 \times 10^{7}$ & $2.314 \times 10^{-6}$ & 4.8 \\
12 & $3 \times 10^{6}$ & $2.314 \times 10^{-6}$ & 2.6 \\
\hline
\end{tabular}

considered as such when making comparisons with models which are not biased by this noise component.

\subsection{Monthly versus 10-day average}

One difficulty in performing a study such as this one is that typically campaigns only last a few days. When performing comparisons from data collected during the campaign period with climatalogical models such as the GSWM, a concern is that the observations during the campaign period may not accurately represent the mean structure observed during a full month or season. To provide some indication as to how well the observations taken during the campaign period represent the state of the atmosphere during January 1993, data from selected sites were analyzed for the full month of January 1993. The results of this analysis are shown in Fig. 4. The zonal (east/west direction with eastward positive) results (top) are shown for Adelaide, Saskatoon, and Christmas Island, and the meridional (north/south direction with northward positive) results (bottom) are shown for Urbana, Robsart, and Kauai. While there are some differences between the results obtained from the two time-periods, as one would expect, these differences are typically less than $5 \mathrm{~m} \mathrm{~s}^{-1}$ for the amplitudes and $1 \mathrm{~h}$ for the phases. From Fig. 4 it can be argued that the mean and tidal structure observed during the campaign period represents the structure of these components during the month of January 1993.

\section{Results}

As was discussed previously, all of the ground-based data presented herein were analyzed utilizing a linear least-squares fit. The model which was fitted to a majority of the data consisted of a mean and 12-h, 24-h, and 48-h sinusoidal components. In cases where a full 24-h of local-time coverage was not available a modified model was fitted to the data. For Millstone Hill and Arecibo, only mean and $12-\mathrm{h}$, and 48-h components were fitted to the data, and for Jicamarca only a 48-h component was fit to the data. It is possible that due to the reduced local-time coverage, some aliasing may occur. The amplitudes and phases which resulted from these fits to the aforementioned components were assumed to be associated with the semidiurnal and diurnal tides and the quasi-two-day wave. In the 

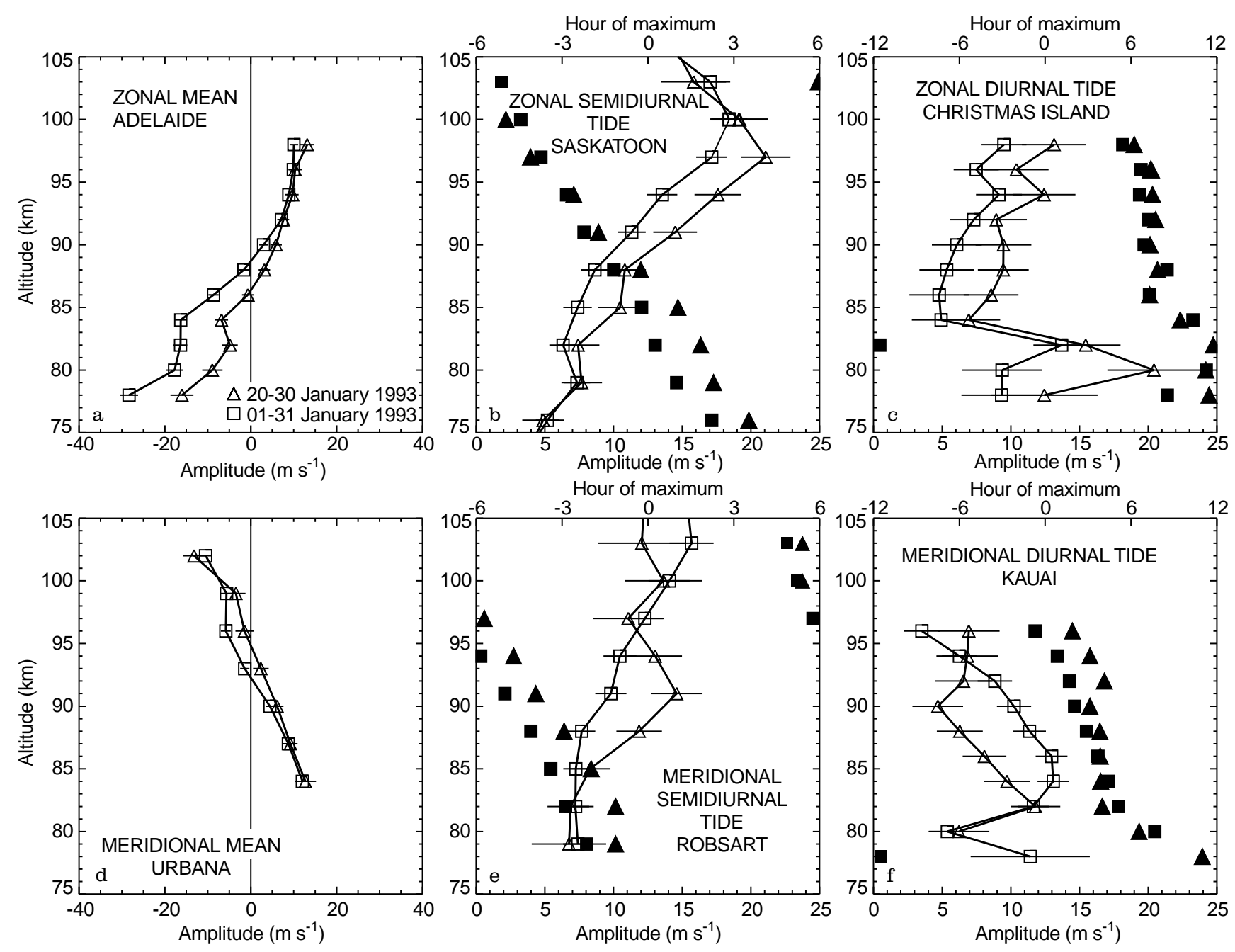

Fig. 4a-f. A comparison of horizontal wind profiles versus altitude analyzed 20-30 January 1993 (triangles) and 1-31 January 1993 (squares). The results are shown for: a Adelaide zonal mean winds, b Saskatoon zonal semidiurnal tide, $\mathbf{c}$ Christmas Island zonal diurnal tide, d Urbana meridional mean winds, e Robsart meridional semidiurnal tide, and f Kauai meridional diurnal tide. Open symbols represent mean or tidal amplitude $\left(\mathrm{m} \mathrm{s}^{-1}\right.$; bottom scale) while the phases for the harmonic components are indicated by filled symbols (hour of maximum in solar local time; top scale) following sections results from these fits in addition to UARS data, which were analyzed separately, are presented and compared with results from the GSWM.

\subsection{Mean winds}

Figure 5 shows a latitude cross section of the zonal mean winds for an altitude of $105 \mathrm{~km}$ (top) and $90 \mathrm{~km}$ (bottom). The data from the GSWM, HRDI, and WINDII are shown for altitudes of 90 and $105 \mathrm{~km}$ while the ground-based observations indicated in Fig. 5 are for the closest available altitude within $\pm 5 \mathrm{~km}$ of the indicated altitude. The GSWM data shown on these plots are the zonal mean winds used for the quasi-twoday wave simulations discussed later in this report and were taken from the empirical model of Portnyagin and Solov'yeva (1992a, b) between 80 and $110 \mathrm{~km}$. This empirical model is based upon ground-based meteor and medium-frequency radar data. The assorted groundbased measurements shown in this figure represent a temporal average computed over 10 days of data, the WINDII measurements are temporal/zonal averages computed for December 1992 through February 1993 and the HRDI measurements are a temporal/zonal average (Lieberman et al., 1993) computed for the month of January 1993.

The zonal mean winds at $90 \mathrm{~km}$ (bottom panel of Fig. 5) show surprisingly good agreement between the empirical model, HRDI, and WINDII data at all latitudes. The structure of the zonal mean wind is indicative of a moderate eastward jet $\left(35 \mathrm{~m} \mathrm{~s}^{-1}\right)$ at midlatitudes in the southern hemisphere which reverses in the subtropics and returns to a somewhat weaker eastward flow in the northern hemisphere. A majority of the ground-based observations lie within $5-10 \mathrm{~m} \mathrm{~s}^{-1}$ of the UARS observations and the empirical model; this should be considered good agreement, as the estimated 


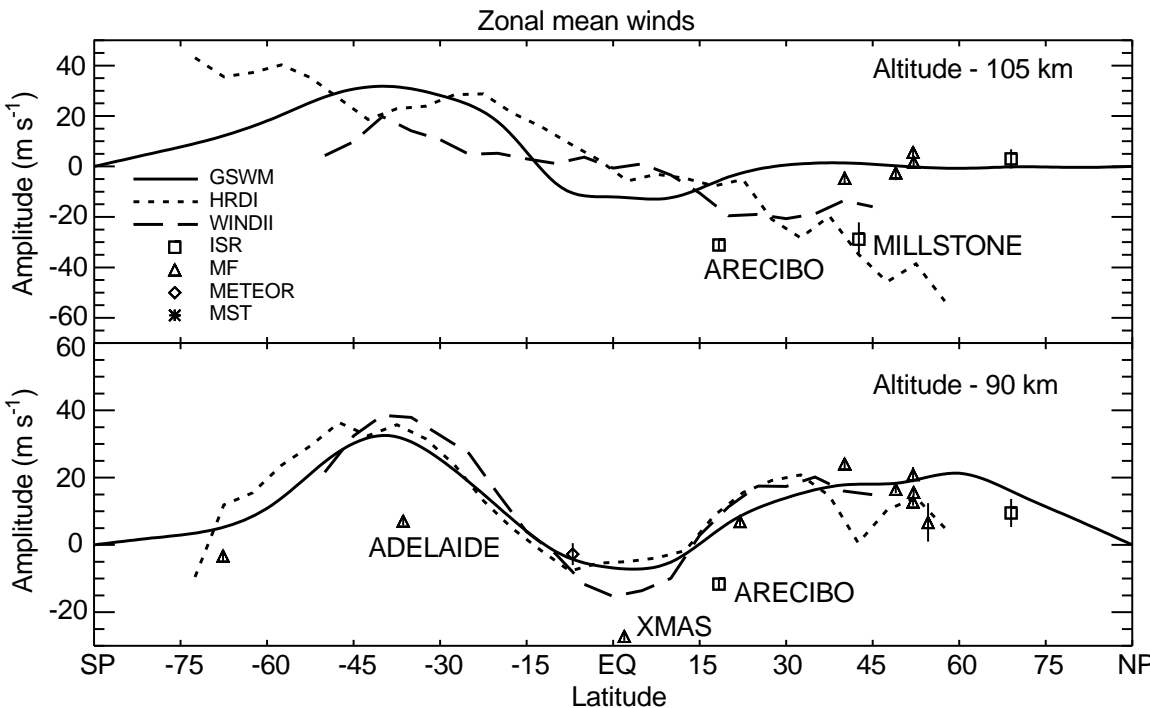

Fig. 5. A latitude cross section of zonal mean winds for an altitude of $105 \mathrm{~km}$ (top) and 90 $\mathrm{km}$ (bottom). The mean winds are shown from the GSWM (solid), HRDI (short dash), WINDII (long dash), and the ground-based radar facilities (assorted symbols) uncertainty of the satellite-derived zonal mean winds is about $5 \mathrm{~m} \mathrm{~s}^{-1}$. Additionally, the uncertainty associated with the satellite observations, due to systematic aliasing effects, becomes larger towards the poles.

Although a majority of the ground-based observations agree well with the empirical model, HRDI, and WINDII data, there are three notable exceptions: Arecibo $\left(18^{\circ} \mathrm{N}\right)$, Christmas Island $\left(2^{\circ} \mathrm{N}\right)$, and Adelaide $\left(35^{\circ} \mathrm{S}\right)$. The discrepancy at Arecibo can be explained by the moderate vertical shear in the zonal mean wind field between 85 and $96 \mathrm{~km}$ as measured by HRDI and WINDII. The closest measurement to $90 \mathrm{~km}$ at Arecibo was $94 \mathrm{~km}$ and if this point is compared with HRDI and WINDII measurements near $94 \mathrm{~km}$ the difference in estimates of the zonal mean wind is about $5 \mathrm{~m} \mathrm{~s}^{-1}$.

Examination of the vertical profiles of the zonal mean wind field at Christmas Island and Adelaide (not shown) indicate that in both cases the HRDI, WINDII, and the empirical model data are in excellent agreement below $105 \mathrm{~km}$ but that the MF measurements deviate significantly $\left(20-35 \mathrm{~m} \mathrm{~s}^{-1}\right)$ from these data between 85 and $100 \mathrm{~km}$. It is of interest to note that at the lowest few heights, 76-82 km, the Christmas Island and Adelaide MF data are almost identical to the HRDI, WINDII, and empirical model data, but that above $82 \mathrm{~km}$ the MF measurements begin to diverge. This divergence is characterized by amplitudes which are significantly smaller for the MF data than the UARS and empirical model at Adelaide above $85 \mathrm{~km}$. Conversely, at Christmas Island the MF winds are significantly larger (more westward) than the UARS and empirical model results between 82 and $95 \mathrm{~km}$. In the meridional mean wind field the Adelaide, WINDII, and HRDI data are all within a few meters per second of each other above $80 \mathrm{~km}$, while at Christmas Island the MF data are larger $\left(5-15 \mathrm{~m} \mathrm{~s}^{-1}\right)$ than the UARS and empirical model data between 85 and $95 \mathrm{~km}$. Burrage et al. (1996) has found that between 85 and $105 \mathrm{~km}$ the MF radar observations were systematically smaller than the HRDI observations. Additionally, Vincent et al.
(1994) have shown that if receiver saturation of the MF radar system is a problem then the observed wind velocities will be systematically smaller than the actual wind velocities. However, even in cases of severe receiver saturation the estimated velocity is only biased too low by $30 \%$ (Vicent et al., 1994). Such a bias would only serve to account for half of the difference observed at Adelaide. Further investigation of this issue is beyond the scope of this paper.

At Christmas Island, where the MF data are larger than the UARS data, receiver saturation is not a valid explanation for the differences, as it would only serve to bring the MF and UARS data into better agreement. One possible reason for this difference is that the zonal winds change rapidly near the equator and these variations cannot be resolved by the UARS instruments due to the inherent latitudinal averaging. A second possibility is that our 10-day interval may be biased by a long-period intraseasonal oscillation which would be suppressed in the UARS climatologies. Eckermann and Vincent (1994) have reported on the existence of such intraseasonal oscillations with significant amplitudes at Christmas Island.

The top panel of Fig. 5 shows the zonal mean winds at an altitude of $105 \mathrm{~km}$. Clearly evident in this figure is a substantial disagreement in the morphology of the zonal mean winds. Both the HRDI and WINDII measurements indicate a strong latitudinal gradient in the zonal mean winds which progresses from strongly westward winds in the northern hemisphere to strongly eastward winds in the southern hemisphere. Alternatively, the empirical model, used in the GSWM for quasi-two-day wave simulations and labeled GSWM in Fig. 5, indicates a moderate eastward jet peaking at midsouthern-hemisphere latitudes which reverses to a weak westward flow in the subtropics and virtually no zonal flow poleward of $30^{\circ} \mathrm{N}$. With the exception of Millstone Hill and Arecibo, the ground-based radar observations agree with the empirical model. However, this is not surprising, as the empirical model was constructed from 
ground-based radar observations. Some care must be taken in interpreting the empirical model at these altitudes since the MF and meteor radar data used to construct the empirical model are most reliable between 90 and $100 \mathrm{~km}$, while above $100 \mathrm{~km}$ the observations become sparse and the uncertainties in the observations are increased.

The large deviation in the zonal winds at $105 \mathrm{~km}$ observed in the HRDI winds poleward of $40^{\circ}$ in both hemispheres is most likely due to contamination from the semidiurnal tide. The semidiurnal tide becomes a dominant feature in the mid- and high-latitude lower thermosphere poleward of $35^{\circ}$. As the semidiurnal tidal amplitude becomes large, even minor errors in correctly estimating its amplitude from the UARS data can induce significant errors in the estimated zonal wind field. It is also possible that the Millstone Hill and Arecibo results could be affected by a similar aliasing problem. Figure 2 shows the presence of a sidelobe in the Millstone Hill and Arecibo aliasing spectra separated in frequency by one cycle per day from the main lobe. As a result any significant diurnal tidal activity could bias estimates of the zonal mean winds.

\subsection{Semidiurnal tide}

Figure 6 is a latitudinal cross section of the zonal semidiurnal tide at $95 \mathrm{~km}$. Between $45^{\circ} \mathrm{S}$ and $30^{\circ} \mathrm{N}$ the HRDI and WINDII estimates of the zonal semidiurnal tidal amplitude are predominantly larger than the GSWM simulations, in some cases by more than $10 \mathrm{~m} \mathrm{~s}^{-1}$. However, as the combined systematic and random errors for the UARS measurements may reach $10 \mathrm{~m} \mathrm{~s}^{-1}$ for the semidiurnal tide, it is not clear that this difference is statistically significant. Excluding the ground-based observations between $45^{\circ} \mathrm{N}$ and $60^{\circ} \mathrm{N}$, the other ground-based observations are in reasonable agreement with the GSWM and UARS measurements. Examining the data between $45^{\circ} \mathrm{N}$ and $60^{\circ} \mathrm{N}$ we find the mid-latitude ground-based observations of the semidiurnal tide in the northern hemisphere are significantly weaker $(\sim 50 \%)$ than simulations by the GSWM. Poleward of $45^{\circ} \mathrm{N}$ the WINDII observations appear to follow the GSWM results, while the HRDI data agrees better with the ground-based data. However, this is a region where the local-time coverage for UARS is reduced and the errors in the UARS measurements become larger relative to the errors equatorward of these latitudes. The observed phases (bottom of Fig. 6) at these sites show reasonable agreement with the GSWM. A similar trend is found in the meridional semidiurnal tide (not shown).

The phase of the zonal semidiurnal tide observed by HRDI and WINDII exhibits a similar structure in the southern hemisphere, where the phase progresses towards earlier local time from the pole towards the equator. The phase predicted by the GSWM in this region is noisy near the pole, which is a numerical artifact, then moves towards later local time, and near $20^{\circ} \mathrm{S}$ begins to progress to earlier local times. This progression to earlier local times becomes more pronounced with increasing latitude. Between $5^{\circ} \mathrm{N}$ and $25^{\circ} \mathrm{N}$, where the semidiurnal tide is weak, the GSWM, HRDI, and WINDII data indicate the presence of a large latitudinal gradient in the phase of the zonal semidiurnal tide. In this region, the ground-based radar observations tend to agree with the WINDII estimates of the phase, with the exception of Kauai. However, because the amplitude of the semidiurnal tide is small at Kauai, little if any confidence can be placed on the phase estimate.

To investigate further the large differences in the amplitude of the semidiurnal tide between the GSWM and ground-based radar measurements in the northern hemisphere we have included Fig. 7. In it the vertical structure of the meridional semidiurnal tide, both the amplitude (left) and phase (right), are shown for a latitude band from $49^{\circ} \mathrm{N}-55^{\circ} \mathrm{N}$ (top) and $40^{\circ} \mathrm{N}-45^{\circ} \mathrm{N}$ (bottom). Evident in the amplitude results $\left(49^{\circ} \mathrm{N}-55^{\circ} \mathrm{N}\right)$

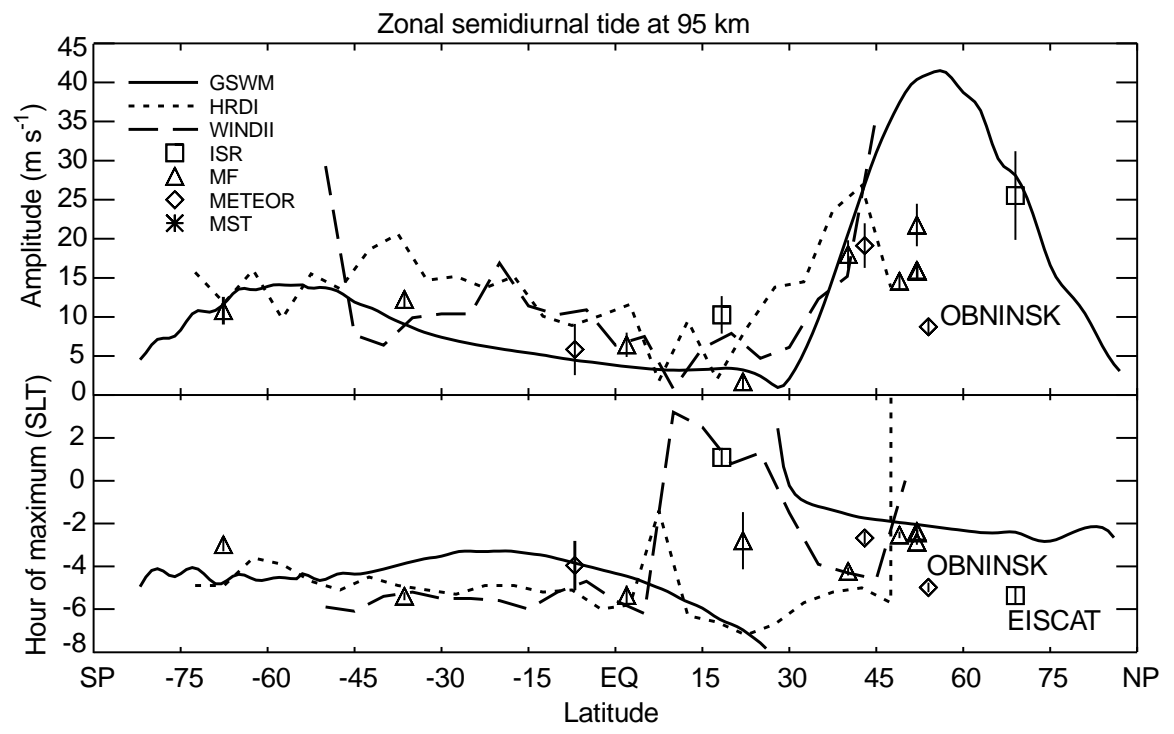

Fig. 6. A latitude cross section of the zonal semidiurnal tide at $95 \mathrm{~km}$. The top panel shows the tidal amplitude and the bottom panel shows the tidal phase. The key for the plot is the same as for Fig. 5 

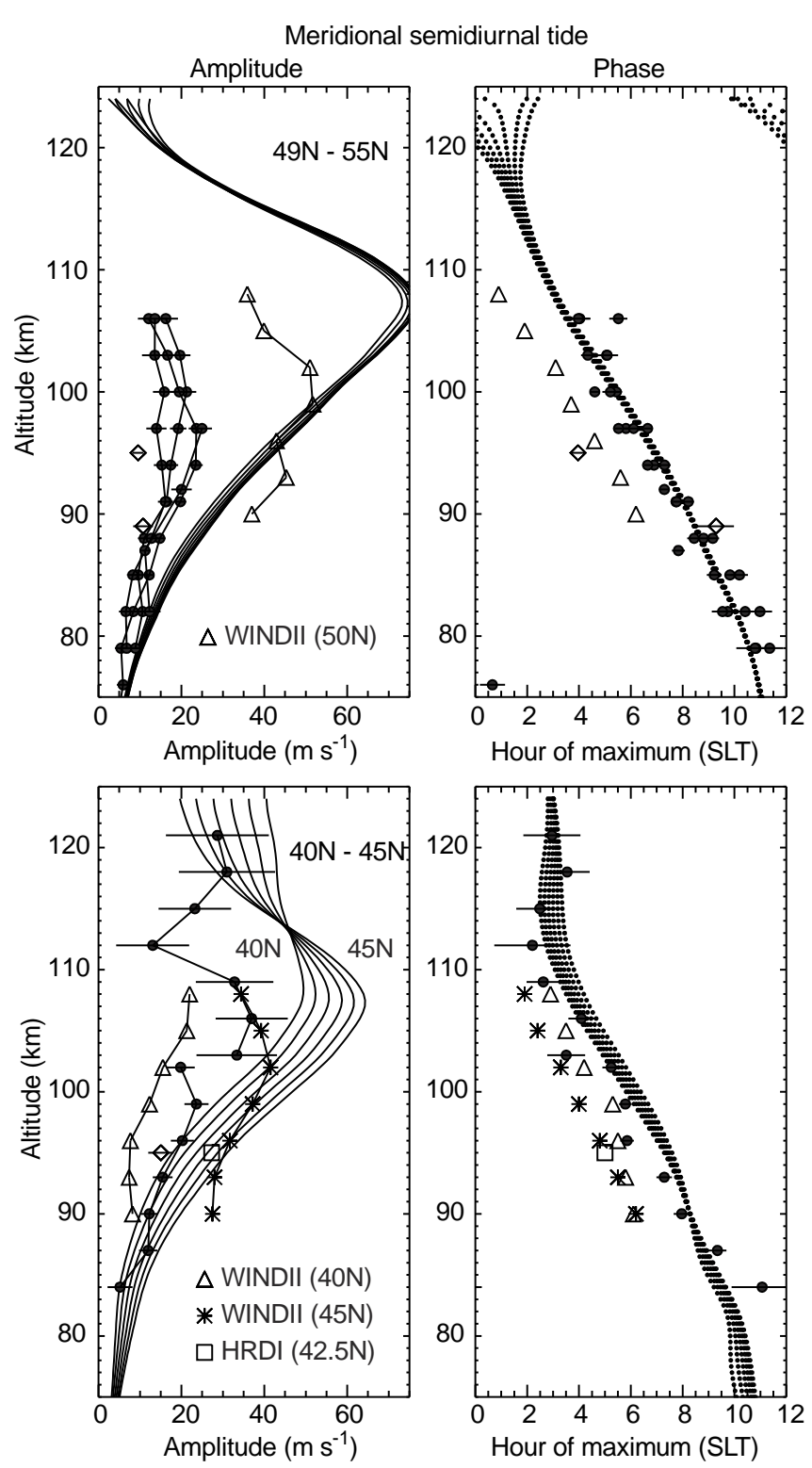

Fig. 7. The amplitude (top left) and phase (top right) of the meridional semidiurnal tide from $49-55^{\circ} \mathrm{N}$ are shown for Sylvan Lake, Saskatoon, Collm, Robsart (all filled circles), Obninsk, Juliusruh (diamonds), WINDII at $50^{\circ} \mathrm{N}$ (triangles) and the GSWM (amplitude: solid line, phase: dots). The amplitude (bottom left) and phase (bottom right) of the meridional semidiurnal tide from $40-45^{\circ} \mathrm{N}$ are shown for Urbana (below $103 \mathrm{~km}$ ), Millstone Hill (above $103 \mathrm{~km}$ ), Durham (diamond at $95 \mathrm{~km}$ ), WINDII at $40^{\circ} \mathrm{N}$ (triangles), WINDII at $45^{\circ} \mathrm{N}$ (asterisks), HRDI at $42.5^{\circ} \mathrm{N}$ (square at $96 \mathrm{~km}$ ) and the GSWM (amplitude: solid line, phase: dots)

is that the ground-based measurements are in good agreement and about $50 \%$ weaker than the WINDII measurements, which are about $30 \%$ weaker than the GSWM simulations above $100 \mathrm{~km}$. However, excluding Obninsk, the ground-based radar measurements of the phase are nearly identical to the GSWM simulations. The slope of the WINDII phase is close to that indicated by the GSWM, but the absolute position of the phase occurs about $2 \mathrm{~h}$ earlier than the GSWM simulations or ground-based radar measurements.
The bottom two plots in Fig. 7 are similar to the top two except for latitudes from $40^{\circ} \mathrm{N}$ to $45^{\circ} \mathrm{N}$. The GSWM simulations indicate that the amplitude of the meridional semidiurnal tide possesses a strong latitudinal gradient in the lower thermosphere. This latitudinal gradient is also present in the WINDII data, and can also be observed in the GSWM simulations shown in Fig. 6. Between 90 and $108 \mathrm{~km}$ the ground-based and HRDI observations of the amplitude of the meridional semidiurnal tide lie between the amplitude estimated from the WINDII data at $40^{\circ} \mathrm{N}$ and $45^{\circ} \mathrm{N}$ with the observations at $40^{\circ} \mathrm{N}$ as the lower bound on the tidal amplitude and the observations at $45^{\circ} \mathrm{N}$ as the upper bound. The GSWM simulations are similar in shape to the WINDII observations as the amplitude of the semidiurnal tide increases with increasing latitude. Additionally, the WINDII and ground-based radar measurements indicate that the amplitude of the semidiurnal tide is growing with increasing altitude until $\sim 102 \mathrm{~km}$, where a maximum of $40 \mathrm{~m} \mathrm{~s}^{-1}$ is observed. A similar feature is observed in the GSWM simulations; however, the GSWM simulations indicate a more rapid growth with altitude than the observations and peak at $108 \mathrm{~km}$ with an amplitude near $65 \mathrm{~m} \mathrm{~s}^{-1}$.

Comparisons of the estimated phases of the meridional semidiurnal tide, shown in the lower right panel of Fig. 7, indicate a reasonable agreement in the slope of the phases; however, there again appears to be a systematic offset in the absolute location of the phase estimated from the WINDII observations. As was observed between $49^{\circ} \mathrm{N}$ and $55^{\circ} \mathrm{N}$ the WINDII phases occur $1-2 \mathrm{~h}$ earlier than the GSWM simulations. At $95 \mathrm{~km}$ the HRDI measurements also agree with the WINDII measurements. The ground-based measurements, although somewhat scattered, do lie within a few hours of the GSWM simulations.

The vertical structure of the semidiurnal tide shown in Fig. 7 is not unlike previous observations of the semidiurnal tide. Portnyagin et al. (1994) reported on the structure of the semidiurnal tide in this latitude and altitude region using data collected during the DYANA campaign. The DYANA campaign ran from 15 January to 15 March 1990. The amplitude structure of the semidiurnal tide observed during this period (Fig. 7; Portnyagin et al., 1994) between $50^{\circ} \mathrm{N}$ and $55^{\circ} \mathrm{N}$ indicates the amplitude of the semidiurnal tide is increasing with altitude from 80 through $105 \mathrm{~km}$. This is consistent with the GSWM simulation presented in Fig. 7. However, the estimated semidiurnal amplitudes ranged from $\sim 10 \mathrm{~m} \mathrm{~s}^{-1}$ at $80 \mathrm{~km}$ to between 15 and $35 \mathrm{~m} \mathrm{~s}^{-1}$ at $105 \mathrm{~km}$, which is about $50 \%$ smaller than the GSWM simulations at the upper altitudes. Additional measurements of the zonal semidiurnal tide taken at Collm $\left(52^{\circ} \mathrm{N}\right)$ (Schminder et al., 1989) from 1983 through 1988 indicate a tidal amplitude between 15 and $20 \mathrm{~m} \mathrm{~s}^{-1}$ at $93 \mathrm{~km}$ during January. Observations made at Saskatoon $\left(52^{\circ} \mathrm{N}\right)$ during 1985 (Manson et al., 1989) indicate the presence of a larger semidiurnal tide in the lower thermosphere than was observed at Collm during the same tide period. Manson et al. (1989) observed a semidiurnal tidal amplitude during January 1985, that 
grows vertically and reaches a maximum amplitude $35 \mathrm{~m} \mathrm{~s}^{-1}$ at an altitude between 100 and $105 \mathrm{~km}$. Other comparisons made between a medium-frequency radar and a Fabry-Perot interferometer at Saskatoon (Phillips et al., 1994; Manson et al., 1997) indicate that similar tidal amplitudes are obtained from the two instruments. Again the vertical structure of the semidiurnal tide observed at Saskatoon during January 1985 is similar in structure to that simulated by the GSWM, but the observed amplitudes are about 50\% smaller than the model simulations.

At slightly lower latitudes, observations of the zonal semidiurnal tide from Garchy $\left(47^{\circ} \mathrm{N}\right)$ and Monpazier $\left(44^{\circ} \mathrm{N}\right)$ using meteor radars indicate an amplitude which maximizes between 95 and $100 \mathrm{~km}$ with an amplitude of nearly $30 \mathrm{~m} \mathrm{~s}^{-1}$ during January (Manson et al., 1989). However, a very different vertical structure was observed during the DYANA campaign at Durham $\left(42^{\circ} \mathrm{N}\right)$ Bologna $\left(45^{\circ} \mathrm{N}\right)$, and Khabarovsk $\left(49^{\circ} \mathrm{N}\right)$. During this period the amplitude of the semidiurnal tide was nearly invariant with altitude and the observed amplitude was typically $15 \mathrm{~m} \mathrm{~s}^{-1}$ between 85 and $100 \mathrm{~km}$.

Figure 8 is a comparison between the GSWM and incoherent-scatter radar observations of the meridional semidiurnal tide at high latitudes. From these observations at EISCAT $\left(69^{\circ} \mathrm{N}\right)$ and Sondrestrom $\left(67^{\circ} \mathrm{N}\right)$ it is difficult to obtain a clear picture of the semidiurnal tide during this time-period. Between 100 and $105 \mathrm{~km}$ the EISCAT and Sondrestrom data agree well with the GSWM simulations. Above $105 \mathrm{~km}$ the observations diverge where the Sondrestrom data agree with the GSWM simulations up to $112 \mathrm{~km}$ and above this altitude the GSWM tends toward the EISCAT observations. One marked difference in these data are that the

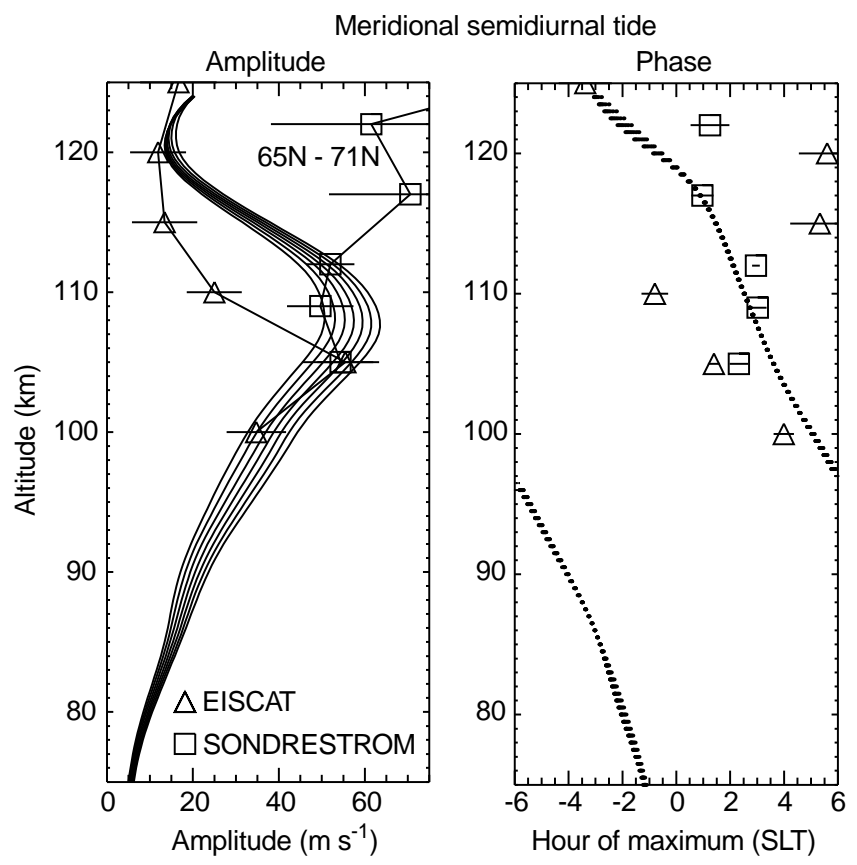

Fig. 8. A comparison of the GSWM meridional semidiurnal tide at high latitudes $\left(65^{\circ} \mathrm{N}-71^{\circ} \mathrm{N}\right)$ with observations from the EISCAT $\left(69^{\circ} \mathrm{N}\right)$ and Sondrestrom $\left(67^{\circ} \mathrm{N}\right)$ incoherent-scatter radars
Sondrestrom observations indicate the presence of a semidiurnal tide which is growing with altitude throughout the altitude range from 105 to $125 \mathrm{~km}$ and exceeds $70 \mathrm{~km}$ above $120 \mathrm{~km}$. Conversely, the EISCAT measurements indicate the presence of a semidiurnal tide which obtains a peak amplitude of $50 \mathrm{~m} \mathrm{~s}^{-1}$ near $105 \mathrm{~km}$ and is suppressed above this altitude. One possible reason for the difference between the observed amplitudes and the GSWM results is that the GSWM does not include any auroral forcing at the high latitudes.

The phase structure of the semidiurnal tide observed at the high latitudes, shown in Fig. 8, is not particularly well organized. While the observed semidiurnal phases are within $3 \mathrm{~h}$ or so of the GSWM simulations, their vertical structure is not in agreement with the GSWM simulations. In particular, the Sondrestrom measurements indicate the presence of a very long vertical wavelength disturbance, while the EISCAT measurements possess a similar vertical phase structure as the GSWM simulations below $110 \mathrm{~km}$, but above $110 \mathrm{~km}$ there is a dramatic phase shift.

Previous observations of the semidiurnal tide at high latitudes have been made by Tetenbaum et al. (1986) and Brekke et al. (1994) during January. The observations made by the former were collected using the MST radar located at Poker Flat, Alaska $\left(65^{\circ} \mathrm{N}, 147^{\circ} \mathrm{W}\right)$ where the MST radar was operated as a meteor radar. Data were collected for 4 years and results for the semidiurnal tide are shown for January-February 1983 and the three winter months of 1984 (DJF). These data indicate the presence of a semidiurnal tide between 75 and $105 \mathrm{~km}$ with a well-defined vertical phase structure and an amplitude between 5 and $15 \mathrm{~m} \mathrm{~s}^{-1}$. The phase of the semidiurnal tide observed at Poker Flat is indicative of an upward-propagating disturbance, with a progression towards earlier local times with increasing altitude, where the amplitude maximum occurs at 11 SLT for an altitude of $75 \mathrm{~km}$ and 6 SLT for $95 \mathrm{~km}$. These phases agree very well with the GSWM simulations. The observations described by Brekke et al. (1994) were collected using the EISCAT incoherent-radar system between 1987 and 1991. These data were selected to include only quiet-time data and as a result only 3 days of winter data were available. The results of this study indicate the presence of a semidiurnal tide of 35$85 \mathrm{~m} \mathrm{~s}^{-1}$ between 80 and $120 \mathrm{~km}$. However, due to the minimal amount of data available it is difficult to assign a high level of confidence to these results.

As the vertical wavelength associated with the meridional semidiurnal tide near its peak amplitude at mid-latitudes appears to agree well with the vertical wavelength predicted by the GSWM (Fig. 7), a simple linear least-squares analysis has been performed to the observed and modeled phases between 85 and $100 \mathrm{~km}$ to estimate these vertical wavelengths. Figure 9 shows the results of these fits where north latitude is indicated on the vertical axis and the estimated vertical wavelength is indicated on the horizontal axis. The vertical wavelength associated with the $(2,4),(2,5)$ and $(2,6)$ semidiurnal tidal modes computed from the classical linearized perturbation equations (Forbes, 1995), assuming an 


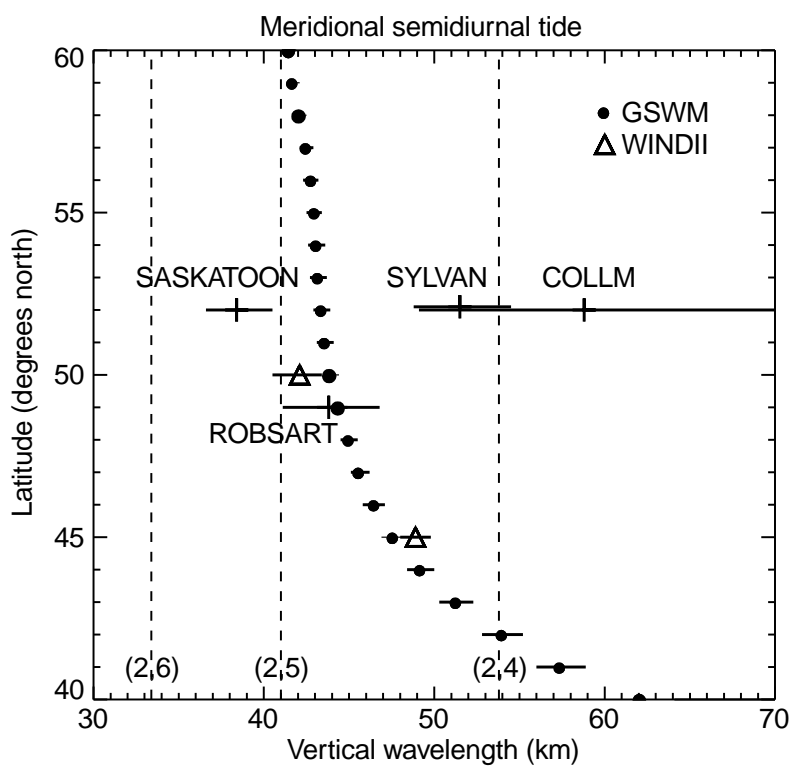

Fig. 9. Estimated vertical wavelength of the meridional semidiurnal tide between 80 and $110 \mathrm{~km}$. The vertical wavelength for the $(2,4)$, $(2,5)$ and $(2,6)$ semidiurnal tidal modes computed from classical tidal theory are provided as a reference (dashed lines)

isothermal atmosphere of $256 \mathrm{~K}$, are indicated in Fig. 9 by the vertical lines (dashed). It should be noted that strictly speaking, classical tidal theory is invalid in the mesosphere and lower thermosphere due to mean winds, temperature gradients and viscous dissipation. Therefore, the vertical wavelengths indicated in Fig. 9 should be interpreted for reference only. The vertical wavelength of the semidiurnal tide predicted by the GSWM (filled circles) decreases with increasing latitude from $62 \mathrm{~km}$ at $40^{\circ} \mathrm{N}$ to $40 \mathrm{~km}$ at $60^{\circ} \mathrm{N}$. The estimated vertical wavelength of the semidiurnal tide measured by WINDII and at Robsart agree very well with the vertical wavelength predicted by the GSWM. Additionally the estimated vertical wavelength from the other groundbased measurements are reasonable when one considers the sensitivity in estimating a $49-60-\mathrm{km}$ vertical wavelength from $15 \mathrm{~km}$ of observations. Clearly evident in Fig. 9 is the agreement between the WINDII estimates of the vertical wavelength of the semidiurnal tide and the GSWM model simulations. At both $45^{\circ} \mathrm{N}$ and $50^{\circ} \mathrm{N}$ the WINDII estimated vertical wavelengths are separated from the GSWM simulation only by a few kilometers.

Based upon the observations reported in this paper and previous observations we conclude that the semidiurnal tide near its peak amplitude $\left(\sim 105 \mathrm{~km}, 55^{\circ} \mathrm{N}\right)$ in the lower thermosphere is overestimated by the GSWM. The degree of overestimation ranges from $25 \%$ to $50 \%$ and depends upon which observational data set is used for the baseline. To understand why the GSWM amplitudes are too large, four numerical experiments were performed. In two of these the background zonal mean winds were modified using observational data from the National Meteorlogical Center (NMC) (Randel, 1994) in the stratosphere and UARS data in the mesosphere. In these two experiments the amplitude of the semidiurnal tide at $95 \mathrm{~km}$ was slightly increased. A third experiment consisted in removing the forcing associated with the secondary ozone peak, which occurs near $88 \mathrm{~km}$ (Hagan et al., 1995). Again the results of this simulation indicated an increase in the amplitude of the semidiurnal tide at $95 \mathrm{~km}$ in the mid-latitude northern hemisphere. Moreover, the amplitude increase was between 20 and $30 \mathrm{~m} \mathrm{~s}^{-1}$, indicating that the response due to the secondary ozone peak during January is out of phase with the upward propagating semidiurnal tide. Our final experiment consisted in modifying the specified coefficient of eddy diffusivity. The eddy diffusivity profiles used for the GSWM simulations are shown in Fig. 2 of Hagan et al. 1995) and are derived from the work of Garcia and Solomon (1985). The values of eddy diffusivity range from 75 to $125 \mathrm{~m}^{2} \mathrm{~s}^{-1}$ in the lower thermosphere. However, these values do not exceed $75 \mathrm{~m}^{2} \mathrm{~s}^{-1}$ in the mid- and high-latitude winter hemisphere. These values may be too low, since more realistic eddy diffusivity may approach $200 \mathrm{~m}^{2} \mathrm{~s}^{-1}$ (Burrage et al., 1995; Geller et al., 1997). A numerical experiment has been performed to determine the role an increased eddy dissipation profile will play in the structure of the semidiurnal tide in the lower thermosphere. Figure 10 illustrates the altitude profile of the latitudinally invariant eddy diffusivity profile used for our numerical experiment. To quantify the change in the amplitude of the meridional semidiurnal tide due to the modified eddy diffusivity profile, Fig. 11 illustrates the amplitude of the vector difference between the base case and the case with the modified eddy diffusivity profile. Positive values in Fig. 11 indicate that the base-case semidiurnal tide was larger than the case with the constant eddy diffusivity and hence the increased diffusivity caused a decrease in

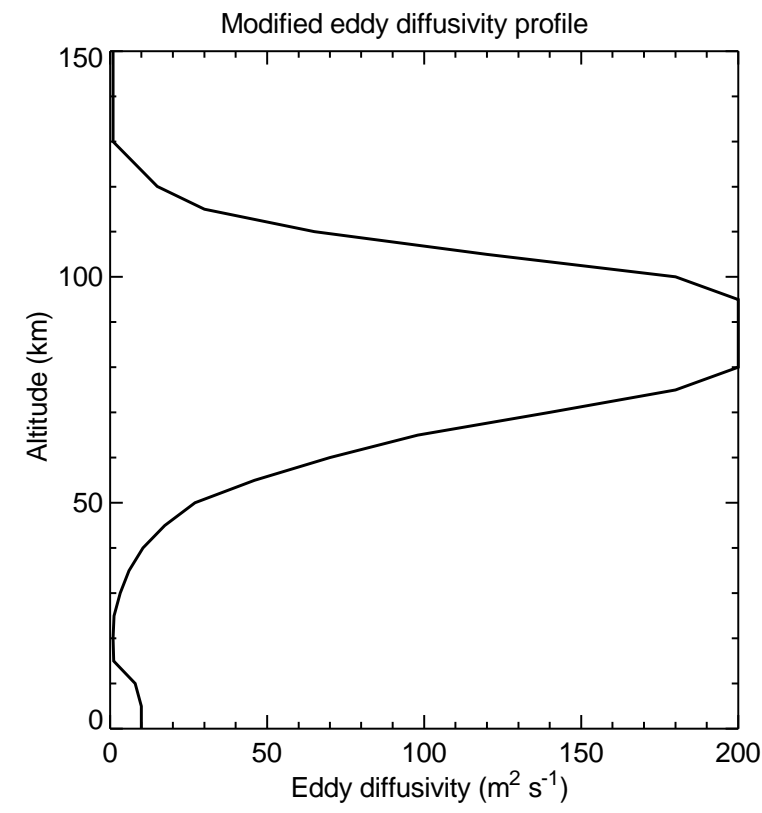

Fig. 10. The vertical profile of modified eddy dissipation used for our numerical experiments regarding the semidiurnal tide. This profile is latitudinally invariant 


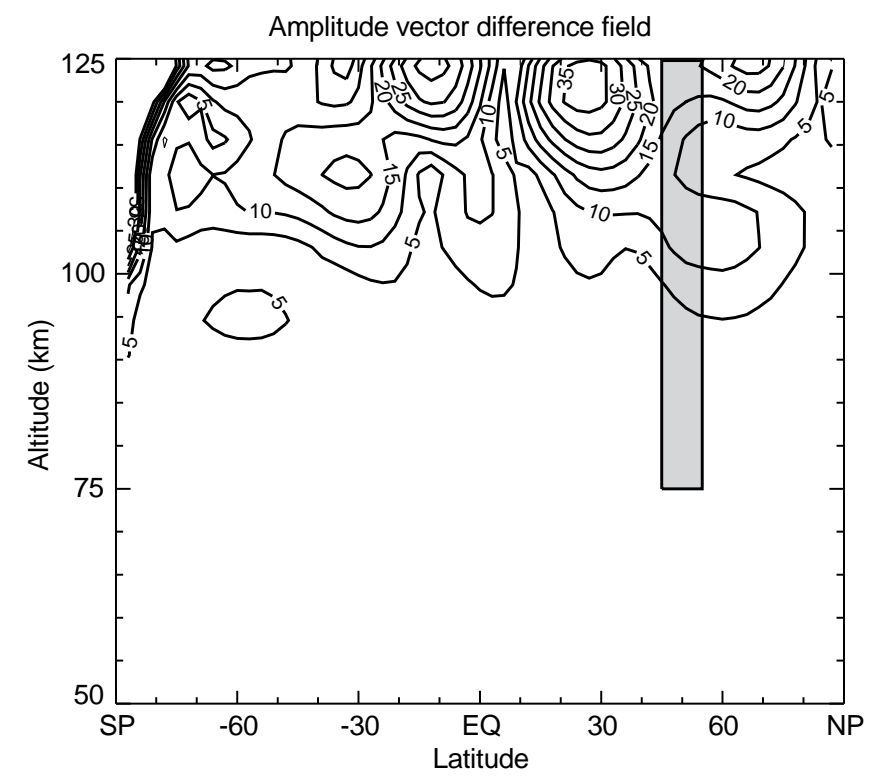

Fig. 11. Amplitude of the vector difference in simulated meridional semidiurnal tide from the GSWM using the base-case eddy diffusivity profile and a modified eddy diffusivity profile with a maximum value of $200 \mathrm{~m}^{2} \mathrm{~s}^{-1}$ (see text for details). The amplitude contours are in $\mathrm{m} \mathrm{s}^{-1}$ and a positive value indicates the base-case amplitude is larger, while a negative value indicates the base-case amplitude is smaller than the case with the modified eddy diffusivity profile. The shaded region indicates the geographic region shown in Fig. 7

the amplitude of the semidiurnal tide. From Fig. 11 it is obvious that the largest absolute amplitude differences occurred above $100 \mathrm{~km}$ and the effect was to decrease the amplitude of the semidiurnal tide. The shaded region of Fig. 11 indicates the location of the geographic region where the data from Fig. 7 were collected. Examination of Fig. 11 in this region indicates that the increased eddy diffusivity profile caused a decrease of about $15 \mathrm{~m} \mathrm{~s}^{-1}$ in the amplitude of the meridional semidiurnal tide between 105 and $110 \mathrm{~km}$. While the GSWM simulations with the increased eddy diffusivity levels are in better agreement with observations these results are still about $10 \mathrm{~m} \mathrm{~s}^{-1}$ larger than the WINDII observations which are significantly larger than the ground-based observations. In addition to changing the structure of the semidiurnal tide, a modified eddy diffusivity profile will also change the structure of the diurnal tide. This effect has been examined by Geller et al. (1997).

\subsection{Diurnal tide}

Figure 12 shows a latitude cross section of the meridional diurnal tide at $95 \mathrm{~km}$. The amplitude (top) and phase (bottom) plots have the same key as Fig. 6. The most striking feature in Fig. 12 is the large discrepancy between the amplitude of the diurnal tide as estimated from the HRDI and WINDII instruments and that simulated by the GSWM. However, discussion of this large amplitude difference is deferred to later in this section. Also evident in Fig. 12 is the latitudinal asymmetry associated with the meridional diurnal tide, which is characterized by a symmetric amplitude profile and a $180^{\circ}$ shift in the phase near the equator where the amplitude becomes zero. Both the UARS data and the GSWM indicate that the meridional diurnal tide is weak near the equator, then increases in amplitude with increasing latitude, maximizing near $20^{\circ}$ latitude, and decreases in amplitude towards the poles. In examining the amplitude structure of the diurnal tide between the equator and $40^{\circ}$ latitude two features become apparent in the GSWM simulations. First, the peak diurnal amplitude in the northern hemisphere is larger than that in the southern hemisphere, and secondly the amplitude structure of the diurnal tide in the northern hemisphere is broader than that seen in the southern hemisphere. Similar features are observed in the WINDII observations and these features become more apparent when comparing the WINDII observations with the HRDI results, because the latitudinal structure of the HRDI results is specified a priori to be antisymmetric about the

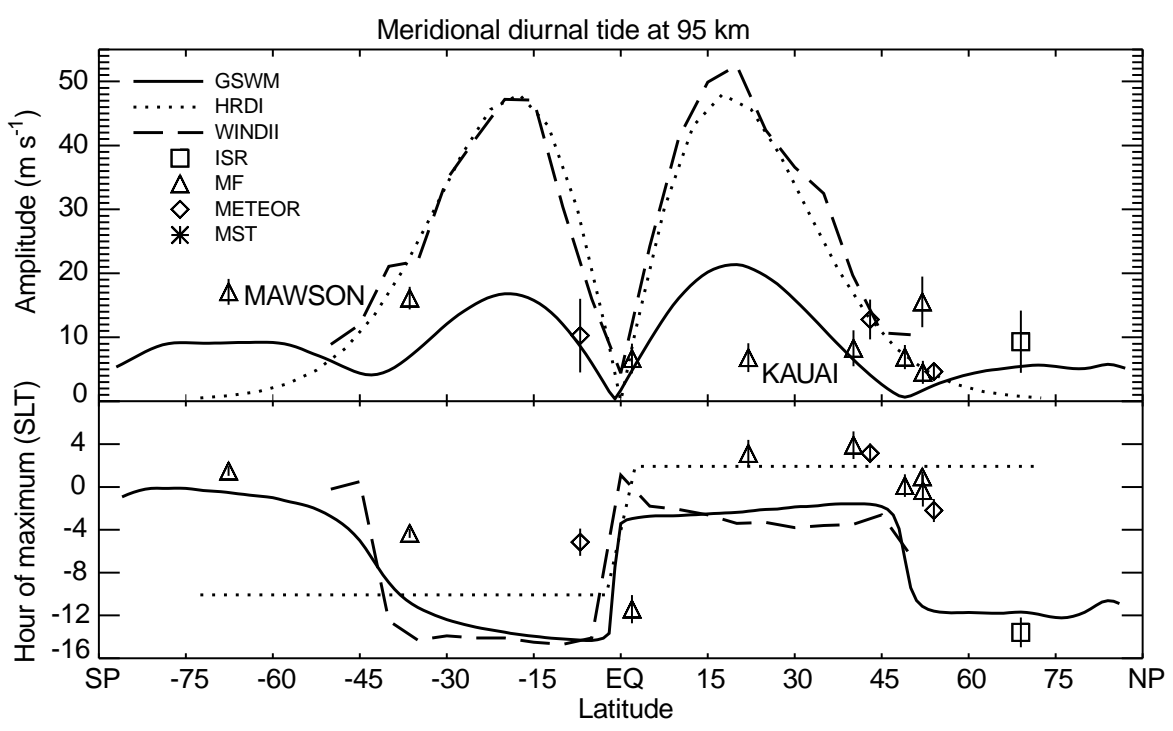

Fig. 12. Same as Fig. 6 except for the meridional diurnal tide 
equator (Hays et al., 1994). This latitudinal asymmetry has also been discussed by Hagan et al. (1994) in relation to GSWM simulations, and can be observed in an assimilative analysis of the HRDI data (Khattatov et al., 1994). To understand more clearly the observational differences associated with the diurnal tide, the following discussion on the extraction of the diurnal tide from the HRDI and WINDII observations has been included. The diurnal tide estimated from the HRDI data is computed on a daily basis by assuming a latitudinal, vertical, temporal, and longitudinal structure. In this analysis, it is assumed that the migrating diurnal tide observed in the mesosphere and lower thermosphere can be described by the $(1,1)$ mode of the migrating diurnal tide computed from classical tidal theory. A model for the diurnal tide is constructed based upon the latitudinal structure of the $(1,1)$ meridional wind expansion function (Forbes, 1995), an empirical vertical amplitude and phase structure (Hays et al., 1994), a period of 1 day and a zonal wavenumber of 1 . The observed HRDI data is then projected onto this model to obtain an estimate of the diurnal tidal amplitude and phase. In contrast, the WINDII diurnal tide is estimated by organizing the observed data into latitude and local-time bins (McLandress et al., 1996). This gridded data is then projected onto a model of the diurnal tide which only enforces a longitudinal and temporal structure (zonal wavenumber $=1$, period $=24 \mathrm{~h}$ ) to obtain an estimate of the diurnal tide. The results in Fig. 12 for HRDI are a vector average of the estimated diurnal tide computed for each day from 20 to 30 January 1993, while the WINDII results are an estimate of the diurnal tide computed for December through February 1993. Although processed using very different procedures, the structure of the HRDI and WINDII estimates of the meridional diurnal tide are remarkably similar. However, there are some differences, the broadening and amplification of the diurnal tide in the northern hemisphere for example, which is captured by the WINDII observations and the GSWM simulations but not the HRDI results. Additionally, poleward of $45^{\circ}$ in each hemisphere the GSWM indicates an increasing diurnal amplitude. Clearly this structure is not present in the HRDI results and serves to indicate that the $(1,1)$ mode assumption does not capture the salient features of the diurnal tide poleward of $45^{\circ}$ during January.

A majority of the ground-based radar observations of the meridional diurnal tide agree well with the GSWM simulations. The agreement becomes even better if the systematic bias of $5-7 \mathrm{~m} \mathrm{~s}^{-1}$ (taken from Table 1) from the underlying geophysical noise is removed. The only major discrepancy in the estimated diurnal tide is observed at Kauai $\left(22^{\circ} \mathrm{N}\right)$, which is of almost negligible amplitude when the geophysical noise is taken into account. This tidal amplitude becomes particularly confusing when compared with an estimate of $20 \mathrm{~m} \mathrm{~s}^{-1}$ by the GSWM and $50 \mathrm{~m} \mathrm{~s}^{-1}$ by HRDI/ WINDII in this region. One possible explanation may be related to the latitudinal effect of the non migrating diurnal tide. This possibility will be discussed in more detail later in this section.
The phase of the diurnal tide, shown in Fig. 12 (bottom), indicates very good agreement between the WINDII estimates and the GSWM simulations. Both the WINDII observations and GSWM simulations indicate the phase of the diurnal tide possesses some degree of latitudinal structure, while the phase estimated from the HRDI observations is invariant with latitude. This invariance is a result of the HRDI processing scheme which enforces a latitudinally invariant tidal phase due to the $(1,1)$ assumption. The HRDI phase occurs about 3-4 h later than the GSWM simulations and the WINDII estimates between $40^{\circ} \mathrm{S}$ and $40^{\circ} \mathrm{N}$. Poleward of this region the GSWM simulations undergo a 10-12-h phase shift which creates an 8-14-h phase difference between the GSWM simulations and the HRDI results. The tidal phases estimated from the ground-based radar data are somewhat scattered, but appear to lie within a few hours of either the HRDI, WINDII, or GSWM data.

As was previously mentioned, the most evident feature of Fig. 12 is the large difference in the amplitude of the diurnal tide as observed by both HRDI and WINDII in comparison with that modeled by the GSWM. The Kauai observations are significantly smaller than the GSWM simulations. While the Kauai estimate of the diurnal tidal amplitude is quite different from either the model simulations or satellite observations, the tidal phase at Kauai agrees well with the phase of the diurnal tide estimated by HRDI at $95 \mathrm{~km}$. Unfortunately, this is just coincidental and is illustrated in Fig. 13.

Figure 13 shows the vertical structure of the meridional diurnal tide between $20^{\circ} \mathrm{N}$ and $23^{\circ} \mathrm{N}$. Notice that

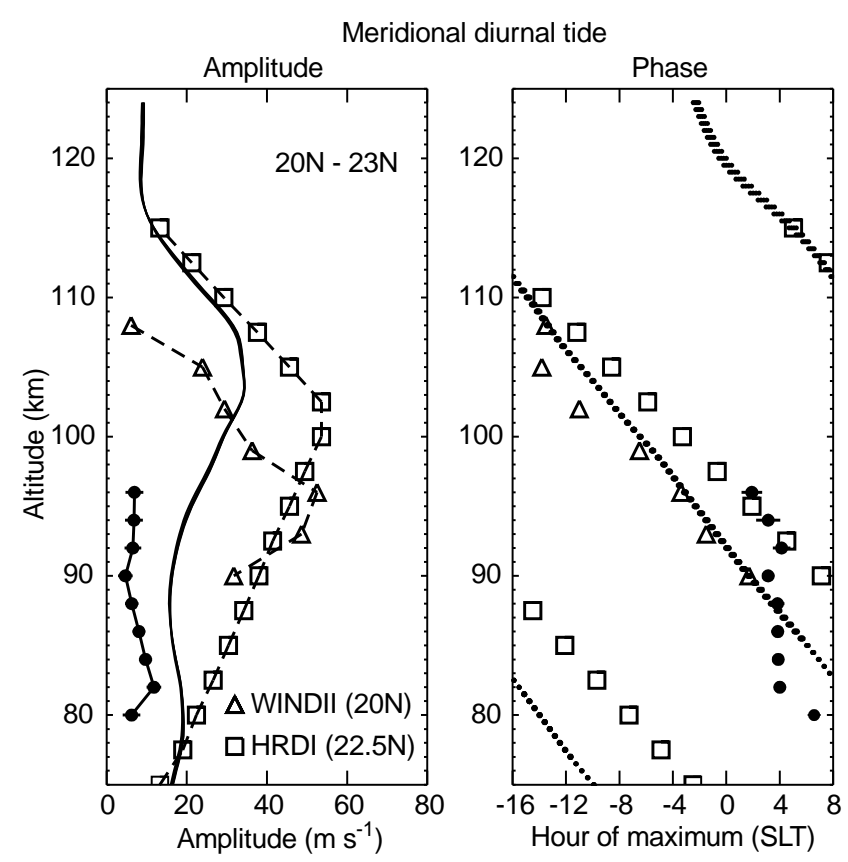

Fig. 13. The amplitude (left) and phase (right) of the meridional diurnal tide from $18^{\circ}$ to $23^{\circ} \mathrm{N}$. The results for Kauai, WINDII at $20^{\circ} \mathrm{N}$ (diamonds), HRDI at $22.5^{\circ} \mathrm{N}$ (squares) and the GSWM (amplitude: solid line, phase: dots) are shown 
near $95 \mathrm{~km}$ the phase (right) of the diurnal tide estimated from the Kauai data agrees well with the HRDI estimate. Clearly, the vertical structure of the diurnal tidal phase estimated from the ground-based radar data is vastly different from the model simulations and satellite observations and the phase agreement at $95 \mathrm{~km}$ is merely coincidental. The satellite observations and model simulations of the diurnal tide indicate a vertical wavelength between 20 and $30 \mathrm{~km}$, while the radar observations indicate the presence of a wave which exhibits little sign of vertical propagation.

The vertical amplitude structure of the diurnal tide, shown in Fig. 13 (left), estimated from the ground-based radar data, satellite observations, and model simulations are, again, quite different from each other. The observations at Kauai are smaller than the UARS observations and GSWM simulations between 80 and $98 \mathrm{~km}$. Near $75 \mathrm{~km}$ the GSWM and HRDI results are in agreement, but HRDI observations increase monotonically to a maximum amplitude of $60 \mathrm{~m} \mathrm{~s}^{-1}$ near $100 \mathrm{~km}$, while vertical amplitude structure from the GSWM simulations is more variable with altitude and maximizes near $105 \mathrm{~km}$ with a value of $30 \mathrm{~m} \mathrm{~s}^{-1}$. The WINDII observations agree with the HRDI observations below $98 \mathrm{~km}$ but above this altitude the WINDII values are $15-20 \mathrm{~m} \mathrm{~s}^{-1}$ weaker than that estimated from the HRDI observations. This difference above $98 \mathrm{~km}$ may be due to the different techniques used by WINDII and HRDI to extract the diurnal tide.

The meridional diurnal tidal amplitudes observed at Kauai for the month of January 1993 (Fig. 4, bottom right) are larger than the amplitudes observed during the campaign period by $5-7 \mathrm{~m} \mathrm{~s}^{-1}$ between 82 and $94 \mathrm{~km}$. Additionally, the vertical phase structure observed during the month of January 1993 is more indicative of a vertically propagating wave feature than was the phase structure observed during the campaign period. A long-term analysis of the Kauai MF radar data has been described by Fritts and Isler (1994); their analysis included data from October 1990 through August
1992. The authors computed estimates of the vertical structure of the diurnal tide for 30 days around the winter solstice for 1990 and 1991 (top panels of Fig. 6 of Fritts and Isler, 1994). These results indicate that the amplitude of the diurnal tide, both zonal and meridional, is between 5 and $20 \mathrm{~m} \mathrm{~s}^{-1}$ from an altitude of 80 to $100 \mathrm{~km}$. The estimated phases for these years were similar to what we see in Fig. 4, where the phase observed during 1990 is considerably more evanescent than that during 1991.

Hagan et al. (1997b) quantify the effects of nonmigrating tidal signatures in the low-latitude mesosphere and lower thermosphere. These migrating tidal results suggest that the nonmigrating diurnal components, when combined with the migrating diurnal tide, result in a diurnal tide which is suppressed in the Pacific longitude sector when compared with the migrating diurnal tide. However, these results cannot explain the phase discrepancies illustrated in Fig. 13.

\subsection{Quasi-two-day wave}

Figure 14 is a latitude cross section of the amplitude of the quasi-two-day wave at an altitude of $95 \mathrm{~km}$ (top) and $87 \mathrm{~km}$ (bottom). The key for Fig. 14 is the same as the amplitude key for Fig. 6. The estimated quasi-twoday wave amplitudes shown in Fig. 14 were determined from a harmonic least-squares fit to a period of $48 \mathrm{~h}$, as was described earlier. Previous observations of the quasi-two-day wave have reported quite a large range of periods ( 45 to $55 \mathrm{~h}$ ) associated with the quasi-two-day wave and it is possible that during this 10-day campaign the period of the quasi-two-day wave was not exactly $48 \mathrm{~h}$. However, power spectra for this 10-day campaign were described by Deng et al. (1996) and indicate that the period of the quasi-two-day wave was close to $48 \mathrm{~h}$, and therefore we expect any errors due to a mismatch between the "true" quasi-two-day wave amplitudes and the observed amplitudes to be small. At $87 \mathrm{~km}$ (bottom)

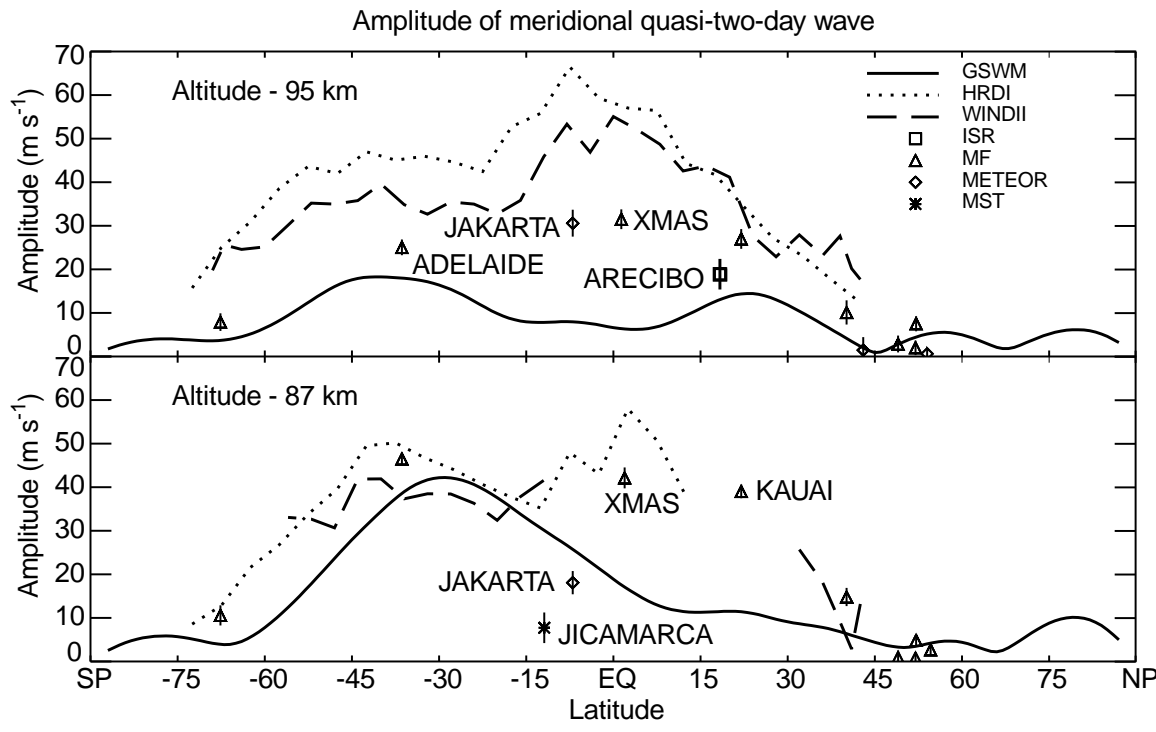

Fig. 14. An altitude cross section of the meridional quasi-two-day wave at $95 \mathrm{~km}$ (top) and $87 \mathrm{~km}$ (bottom). The key is the same as the amplitude key for Fig. 6. 
in the southern hemisphere, the HRDI, WINDII results, and the GSWM simulations show good agreement in the amplitude of the quasi-two-day wave. Additionally, with the exception of a shift in the location of the maximum estimated from the HRDI data poleward, the HRDI data and GSWM simulations show good agreement in the latitudinal structure of the quasi-two-day wave. In the subtropics and equatorial region, the HRDI data indicates the presence of a stronger quasi-two-day wave at $87 \mathrm{~km}$ than the GSWM simulations indicate. Comparison with the ground-based data is mixed, as estimates of the quasi-two-day wave amplitude at Jakarta and Jicamarca are smaller than the GSWM simulation while the Christmas Island and Kauai observations indicate an amplitude close to that estimated from the HRDI observations. At mid-latitudes in the northern hemisphere the ground-based radar data agree with the WINDII observations and the GSWM simulations, indicating that the quasi-two-day wave is negligible in these regions during January. Additionally, while not shown, the EISCAT data also indicates that there is no significant quasi-two-day wave signature present at the high latitudes.

Moving from 87 to $95 \mathrm{~km}$ (top) the differences between the GSWM simulations of the quasi-two-day wave and the HRDI/WINDII observations become more pronounced. The amplitude differences vary between $15 \mathrm{~m} \mathrm{~s}^{-1}$ and $45^{\circ} \mathrm{S}$ to $50 \mathrm{~m} \mathrm{~s}^{-1}$ near the equator. The HRDI and WINDII data are similar in latitudinal structure to what was observed at $87 \mathrm{~km}$. A peak amplitude of $50-60 \mathrm{~m} \mathrm{~s}^{-1}$ in the HRDI and WINDII data is observed near $7^{\circ} \mathrm{S}$. With the exception of Arecibo, the ground-based radar data between $35^{\circ} \mathrm{S}$ and $35^{\circ} \mathrm{N}$ lie somewhere between the GSWM simulations and the HRDI/WINDII observations of the quasitwo-day wave amplitude. Examination of the vertical profile of the quasi-two-day wave amplitude for Arecibo (not shown) indicates that between 94 and $100 \mathrm{~km}$ there is a large shear $\left(\sim 4 \mathrm{~m} \mathrm{~s}^{-1} \mathrm{~km}^{-1}\right)$ and above $100 \mathrm{~km}$ the Arecibo results agree well with the WINDII data.

Figure 15 shows the vertical amplitude (left) and phase structure of the quasi-two-day wave near $7^{\circ} \mathrm{S}$ (top) and $35^{\circ} \mathrm{S}$ (bottom). Near $7^{\circ} \mathrm{S}$ (top), the Jakarta meteor radar data (filled circles) indicates very little amplitude structure (left) as the amplitude is close to $20 \mathrm{~m} \mathrm{~s}^{-1}$ throughout the altitude range from 75 to $98 \mathrm{~km}$. Alternatively, both the HRDI and WINDII observations indicate the presence of a strong shear in the amplitude of the quasi-two-day wave with the largest amplitude observed near $96 \mathrm{~km}$. This is in contrast to the GSWM simulations, which indicate a maximum amplitude near $84 \mathrm{~km}$. However, comparison of the GSWM simulations with the medium-frequency radar data at Adelaide shows excellent agreement (Fig. 15, bottom left). The agreement in the absolute magnitude of quasi-two-day wave is not particularly surprising because the GSWM quasi-two-day wave results must be calibrated. Unlike the GSWM tidal forcing, the forcing mechanism for the quasi-two-day wave is unknown, and the quasi-two-day wave response in the GSWM is calibrated using MF climatalogical results to provide
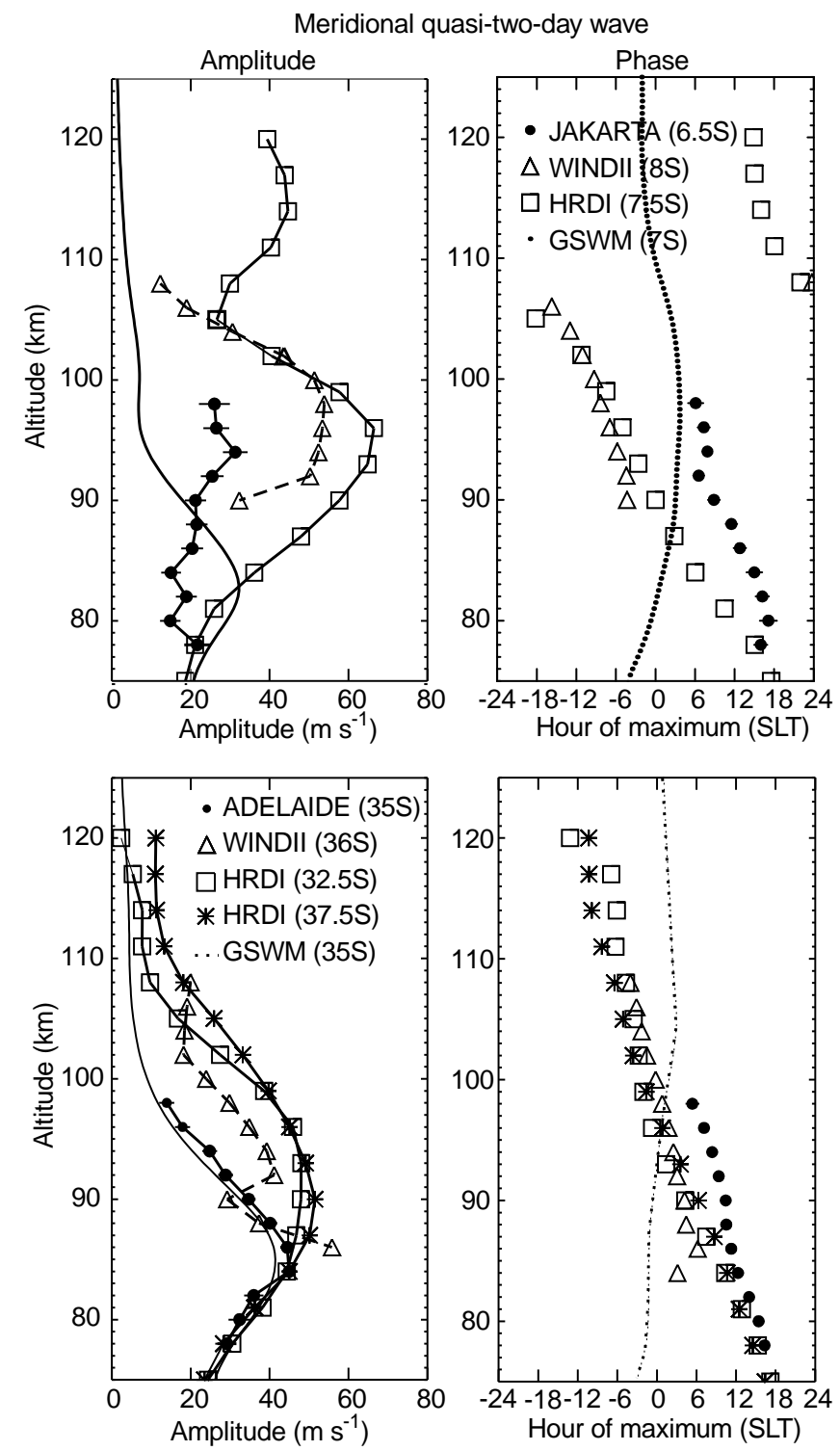

Fig. 15. The vertical structure of the meridional quasi-two-day wave near Jakarta (top) at $6.5^{\circ} \mathrm{S}$ and Adelaide (bottom) at $35^{\circ} \mathrm{S}$. The amplitude (left) and phase (right) are estimated from fits to a period of $48 \mathrm{~h}$

reasonable agreement with observed signatures at lower thermospheric altitudes. This calibration is only to specify the absolute magnitude of the source at the lower boundary and plays no role in either the vertical or latitudinal structure of the quasi-two-day wave response aloft.

It is possible that the differences in the amplitude of the quasi-two-day wave at $95 \mathrm{~km}$ between the model simulations and the satellite observations are related to the magnitude and position of the lower thermospheric reversals in the zonal mean wind field. Hagan et al. (1993) show in a set of numerical experiments relating to the quasi-two-day wave that inclusion of the lowerthermospheric reversals in the zonal mean wind field are necessary to achieve a realistic quasi-two-day wave response in the upper mesosphere. Additionally, it has 
been hypothesized that the reversals in the lowerthermospheric jets serve to reflect the quasi-two-day wave downwards setting up a standing wave. As a result of this standing wave-pattern, the quasi-two-day wave amplitude is increased in the upper mesosphere. Therefore, if the position of the lower-thermospheric reversal in the zonal wind field was shifted equatorward, one might expect an increased quasi-two-day wave response in the equatorial and subtropical regions, as was observed by HRDI and WINDII.

\section{Conclusions}

We have presented observations of the mean winds, tides and the quasi-two-day wave from the lower thermosphere collected during the January 1993 World Day (LTCS-9/MLTCS-5) campaign which lasted for 10 days. With data from 18 ground-based sites and two instruments located on the UARS satellite this data set provides the means to assess the ability of the GSWM to simulate the solar tides and the quasi-two-day wave in the lower thermosphere. Through this comparative study we have found that the GSWM provides a reasonable estimate of the tidal and quasi-two-day wave structure through the lower thermosphere. There are, however, notable exceptions.

The two most evident differences between the observations and the GSWM simulations occurred in the amplitude of the semidiurnal and diurnal tides. In the case of the semidiurnal tide, the GSWM amplitudes were two times larger than the semidiurnal amplitudes measured by radars, utilizing three different techniques, between $45^{\circ} \mathrm{N}$ and $60^{\circ} \mathrm{N}$. Through a simple set of numerical experiments using the GSWM we believe that the eddy diffusivity profile used in the model calculations plays a major role in this difference. By increasing the eddy diffusivity to $200 \mathrm{~m}^{2} \mathrm{~s}^{-1}$ the amplitude of the semidiurnal tide was reduced by $25-35 \%$. While this does not account for the total difference in tidal amplitude it does indicate that an increase in the eddy diffusivity profile can account for much of the amplitude difference. In contrast to the amplitude structure the vertical phase structure observed in this geographic region is nearly identical to that modeled by the GSWM.

The amplitude discrepancy in the diurnal tide between the GSWM and the measurements is a more difficult issue to resolve, particularly because there are some observations which are weaker than the GSWM simulations and some observations which are stronger. However, it does appear that the nonmigrating diurnal tide, which can play a significant role in the structure of the total diurnal tide (migrating + nonmigrating) in this region, may aid the description of some of these differences. Again, while there are large differences in the amplitude, the phase of the GSWM agrees very well with the WINDII observations.

The agreement between the observations and the GSWM simulations for the quasi-two-day wave is latitude and altitude dependent. In the southern hemisphere at altitudes below $90 \mathrm{~km}$ the GSWM simulations and observations are in good agreement. However, above this altitude and in the subtropics, the amplitude of the quasi-two-day wave simulated by the GSWM is significantly weaker than what is observed. It is believed that this difference is due to inaccuracies in the zonal mean wind field used for this simulation. In particular there are very few reliable measurements at lowerthermospheric heights where the zonal mean winds reverse and the westward jet is set up. Because the quasitwo-day wave is sensitive to the zonal mean winds, especially in the lower thermosphere, any deviations in the zonal mean wind field used in the model simulations from the actual conditions during the campaign period will create noticeable differences between the observed and modeled amplitude structure.

In addition to the comparative results between the GSWM simulations and observations we have also described and quantified a number of difficulties which could bias any model measurement comparison. Of particular importance are the systematic amplitude bias and the presence of aliasing. Both of these phenomena are inherent to observational data and cannot be avoided; however, we have provided some estimates of how these phenomena will effect our comparative results.

Acknowledgements. The authors would like to thank J. Isler, D. Fritts, and S. Avery, who provided the Kauai MF data, and R. Woodman and E. Kudeki, who provided the Jicamarca data. This research has been supported by the National Center for Atmospheric Research and NASA grant S-97239-E. The National Center for Atmospheric Research is sponsored by the National Science Foundation. The Arecibo Observatory is operated by Cornell University under a cooperative agreement with the National Science Foundation. The Jakarta meteor radar is operated under a cooperation between RASC, Kyoto University, Japan, and LAPAN and BPPT in Indonesia.

Topical Editor F. Vial thanks H. G. Muller and E. L. Fleming for their help in evaluating this paper.

\section{References}

Brekke, A., S. Nosawa, and T. Sparr, Studies of the E-region neutral wind in the quiet auroral ionosphere, J. Geophys. Res., 99, 8801, 1994.

Briggs, B. H., The analysis of spaced sensor records by correlation techniques, in Handbook for MAP, Ed. SCOSTEP Secretariat, Univ. Illinois, Urbana, pp. 166-186 1984.

Burrage, M., M. E. Hagan, W. R. Skinner, D. L. Wu and P. B. Hays, Long-term variability in the solar diurnal tide observed by HRDI and simulated by GSWM, Geophys. Res. Lett., 22, 2641, 1995.

Burrage, M., W. Skinner, D. Gell, P. Hays, A. Marshall, D. Ortland, A. Manson, S. Franke, D. Fritts, P. Hoff-man, C. McLandress, R. Niciejewski, F. Schmidlin, G. Shepherd, W. Singer, T. Tsuda, and R. Vincent, Validation of mesosphere and lower-thermosphere wind from the high-resolution Doppler imager on UARS, J. Geophys. Res., 101, 10365, 1996.

Deng, W., J. E. Salah, R. R. Clark, S. J. Franke, D. C. Fritts, P. Hoffmann, D. Kuerschner, A. H. Manson, C. E. Meek, D. Murphy, T. Nakamura, S. E. Palo, D. M. Riggin, R. G. Roble, R. Schminder, W. Singer, T. Tsuda, R. A. Vincent, and Q. Zhou, Coordinated global radar observations of tidal and planetary waves in the mesosphere and lower thermosphere during 20-30 January 1993, J. Geophys. Res., 102, 7307, 1997. 
Eckermann, S. D., and R. A. Vincent, First observations of intraseasonal oscillations in the equatorial mesosphere and lower thermosphere, Geophys. Res. Lett., 21, 265, 1994.

Evans, J. V., Incoherent-scatter contributions to studies of dynamics of the lower thermosphere, Rev. Geophys., 16, 195, 1978.

Forbes, J. M., Atmospheric tides 1. Model description and results for the solar diurnal component, J. Geophys. Res., 87, 5222, 1982.

Forbes, J. M., The lower-thermosphere coupling study of the CEDAR and WITS programs, Adv. Space Res., 10, 251, 1990.

Forbes, J. M., Tidal and planetary waves, in The upper mesosphere and lower thermosphere: a review of experiment and theory, Eds. R. M. Johnson, and T. L. Killeen, American Geophysical Union, Geophysical Monograph 87, pp. 67-87, 1995.

Forbes, J. M., and J. E. Salah, Mesosphere-thermosphere tidal coupling during the September 21-25, 1987, LTCS 1 campaign, J. Geophys. Res., 96, 1135, 1991.

Fritts, D. C., and J. R. Isler, Mean motions and tidal and two-day structure and variability in the mesosphere and lower thermosphere over Hawaii, J. Atmos. Sci., 51, 2145, 1994.

Garcia, R. R., and S. Solomon, The effect of breaking gravity waves on the dynamics and chemical composition of the mesosphere and lower thermosphere, J. Geophys. Res., 90, 3850, 1985.

Geller, M. A. (ed.), Wind observations in the middle atmosphere, CNES, Paris, 1994.

Geller, M. A., B. V. Khattatov, V. A. Yudin, and M. E. Hagan, Modeling the diurnal tide with dissipation derived from UARS/ HRDI measurements, Ann. Geophysicae, this issue, 1997.

Hagan, M. E., J. M. Forbes, and F. Vial, Numerical investigation of the propagation of the quasi-two-day wave into the lower thermosphere, J. Geophys. Res., 98, 23193, 1993.

Hagan, M. E., J. M. Forbes, and F. Vial, An updated model of migrating tides in the middle atmosphere: Initial results and measurement comparisons, in Geller 1994.

Hagan, M. E., J. M. Forbes, and F. Vial, On modeling the migrating solar tides, Geophys. Res. Lett., 22, 893, 1995.

Hagan, M. E., J. L. Chang, and S. K. Avery, GSWM estimates of non-migrating tidal effects, J. Geophys. Res., in review, 1997a.

Hagan, M. E., J. M. Forbes, and C. McLandress, Diurnal tidal variability in the upper mesosphere and lower thermosphere, Ann. Geophysicae, this issue, 1997b.

Harris, T. J., A long-term study of the quasi-2-day wave in the middle atmosphere, J. Atmos. Terr. Phys., 56, 569, 1994.

Hays, P. B., V. J. Abreu, M. E. Dobbs, D. A. Gell, H. J. Grassl, and W. R. Skinner, High-resolution Doppler imager on the Upper Atmosphere Research Satellite, J. Geophys. Res., 98, 10713, 1993.

Hays, P. B., D. L. Wu, and The HRDI Science Team, Observations of the diurnal tide from space, J. Atmos. Sci., 51, 3077, 1994.

Khattatov, B., M. Geller, V. Yudin, P. Hayes, S. Franke, D. Fritts, J. Isler, A. Manson, and R. Vincent, Tides in the mesosphere and lower thermosphere derived from HRDI/UARS and comparison with MF radar results, in Geller 1994.

Khattatov, B., M. Geller, V. Yudin, P. Hayes, W. Skinner, M. Burrage, S. Franke, D. Fritts, J. Isler, A. Manson, C. Meek, R. McMurray, W. Singer, P. Horrmann, and R. Vincent, Dynamics of the mesosphere and lower thermosphere as seen by MF and by the high-resolution Doppler imager/UARS, J. Geophys. Res., 101, 10393, 1996.

Lieberman, R. S., M. D. Burrage, D. A. Gell, P. B. Hays, A. R. Marshall, D. A. Ortland, W. R. Skinner, D. L. Wu, R. A. Vincent, and S. J. Franke, Zonal mean winds in the equatorial mesosphere and lower thermosphere observed by the high resolution Doppler imager, Geophys. Res. Lett., 20, 2849, 1993.

Manson, A. H., C. E. Meek, H. Teitelbaum, F. Vial, R. Schminder, D. Kürschner, M. J. Smith, J. F. G., and R. R. Clark, Climatologies of semi-diurnal and diurnal tides in the middle atmosphere $(70-110 \mathrm{~km})$ at middle latitudes $\left(40-55^{\circ}\right), J$. Atmos. Terr. Phys., 51, 579, 1989.
Manson, A. H., F. Yi, G. Hall, and C. Meek, Comparisons between instantaneous wind measurements made at Saskatoon $\left(52^{\circ} \mathrm{N}\right.$, $\left.107^{\circ} \mathrm{W}\right)$ using the colocated medium-frequency radars and Fabry-Perot interferometer instruments: climatologies (19881992) and case-studies, J. Geophys. Res., in press, 1997.

McLandress, C., G. G. Shepherd, and B. H. Solheim, Satellite observations of thermospheric tides: results from the Wind Imaging Interferometer on UARS, J. Geophys. Res., 101, 4093, 1996.

Meek, C. E., A. H. Manson, S. J. Franke, W. Singer, P. Hoffman, R. R. Clark, T. Tusda, T. Nakamura, M. Tsutsumi, M. Hagan, D. C. Fritts, J. Isler, and Y. I. Portnyagin, Global study of northern hemisphere quasi-2-day wave events in recent summers near $90-\mathrm{km}$ altitude, J. Atmos. Terr. Phys., 58, 1401, 1996.

Miyahara, S., Y. I. Portnyagin, J. M. Forbes, and T. V. Solovjeva, Mean zonal acceleration and heating of the $70-$ to $100-\mathrm{km}$ region, J. Geophys. Res., 96, 1225, 1991.

Nakamura, T., D. C. Fritts, J. R. Isler, T. Tsuda, R. A. Vincent, and I. M. Reid, Short-period fluctuations of the diurnal tide observed with low-latitude $\mathrm{MF}$ and meteor radars during CADRE: evidence for gravity wave/tidal interactions, J. Geophys. Res., 1997 in press.

Palo, S. E., and S. K. Avery, Mean winds and the semiannual oscillation in the mesosphere and lower thermosphere at Christmas Island, J. Geophys. Res., 98, 20385, 1993.

Palo, S. E., and S. K. Avery, Observations of the quasi-two-day wave in the middle and lower atmosphere over Christmas Island, J. Geophys. Res., 101, 12833, 1996.

Phillips, A., A. Manson, C. Meek, and E. LLewellyn, A long-term comparison of middle-atmosphere winds measured at Saskatoon $\left(52^{\circ} \mathrm{N}, 107^{\circ} \mathrm{W}\right)$ by a medium-frequency radar and a FabryPerot interferometer, J. Geophys. Res., 99, 12923, 1994.

Portnyagin, Y. I., and T. V. Solov'yeva, An empirical model of the meridional wind in the mesopause/lower thermosphere, 1, a mean monthly emperical model, Ross. Meterol. Gidrol., 10, 28, $1992 a$.

Portnyagin, Y. I., and T. V. Solov'yeva, An empirical model of the meridional wind in the mesopause/lower thermosphere, 2, height-latitude features of basic components of meridional wind seasonal variations, Ross. Meteorol. Gidrol., 11, 29, 1992 b.

Portnyagin, Y. I., N. A. Makaraov, R. P. Chebotarev, A. M. Nikonov, E. S. Kazimirovsky, V. D. Kokourov, V. V. Sidorov, A. N. Fakhrutdinova, G. Cevolani, R. R. Clark, D. Kürschner, R. Schminder, A. H. Manson, C. E. Meek, H. G. Muller, J. C. Stoddart, W. Singer, and P. Hoffmann, The wind regime of the mesosphere and lower thermosphere during the DYANA campaign-II. semi-diurnal tide, J. Atmos. Terr. Phys., 56, 1731, 1994.

Randel, W. J., Observations of the 2-day wave in NMC stratospheric analysis, J. Atmos. Sci., 51, 306, 1994.

Reber, C. A., C. E. Trevathan, R. J. McNeal, and M. R. Luther, Upper Atmosphere Research Satellite (UARS) mission, J. Geophys. Res., 98, 10643, 1993.

Rees, D., J. J. Barnett, and K. Labitzke, (Eds.) $\operatorname{COSPAR}$ International Reference Atmosphere: 1986, vol. 10, Pergamon, New York, 1990.

Roberts, R. A., and C. T. Mullis, Digital Signal Processing, Addison-Wesley, Reading, Mass., 1987.

Roper, R. G., MWR-meteor wind radars, Middle Atmosphere Program Handbook, 13, 124, 1984.

Röttger, J., P. Czechowsky, R. Rüster, and G. Schmidt, VHF radar observations of wind velocities at the Arecibo observatory, $J$. Geophys., 52, 34, 1983.

Salah, J. E., R. M. Johnson, and C. A. Tepley, Coordinated incoherent-scatter radar observations of the semidiurnal tide in the lower thermosphere, J. Geophys. Res., 96, 1071, 1991.

Schminder, R., D. Kürschner, A. H. Manson, and C. E. Meek, Semidiurnal tidal winds at Collm $\left(52^{\circ} \mathrm{N}, 15^{\circ} \mathrm{E}\right)$ and Saskatoon $\left(52^{\circ} \mathrm{N}, 107^{\circ} \mathrm{W}\right)$ over the decade 1978-1988, J. Atmos. Terr. Phys., 51, 623, 1989. 
Shepherd, G. G., G. Thuillier, W. A. Gault, B. H. Solheim, C. Hersom, J. M. Alunni, J. -F. Brun, S. Brune, P. Charlot, L. L. Cogger, D. -L. Desaulniers, W. J. Evans, R. L. Gattinger, F. Girod, D. Harvie, R. H. Hum, D. J. W. Kendall, E. J. Liewellyn, R. P. Lowe, J. Ohrt, P. Pasternak, O. Peillet, I. Powell, Y. Rochon, W. E. Ward, R. H. Wiens, and J. Wimperis, WINDII, the wind imaging interferometer on the Upper Atmosphere Research Satellite, J. Atmos. Sci., 98, 10725, 1993.

Tetenbaum, D., S. K. Avery, and A. Riddle, Observations of mean winds and tides in the upper mesosphere during 1980-1984, using the Poker Flat Alaska, MST radar as a meteor radar, $J$. Geophys. Res., 91, 14539, 1986.

Tsuda, T., A preliminary report on observations of equatorial atmosphere dynamics in Indonesia with radars and radiosondes, J. Meteor. Soc. Japan, 73, 393, 1995.

Tsuda, T., T. Nakamura, and S. Kato, Mean winds observed by the Kyoto meteor radar in 1983-1985, J. Atmos. Terr. Phys., 49, 461, 1987.

Vincent, R. A., and D. Lesicar, Dynamics of the equatorial mesosphere: first results with a new generation partial reflection radar, Geophys. Res. Lett., 18, 825, 1991.
Vincent, R. A., D. A. Holsworth, I. M. Reid, and M. A. Cervera, Spaced-antenna wind measurements: the effects of signal saturation, in Geller, 1994.

Virdi, T., and P. Williams, Altitude variations in amplitude and phase of tidal oscillations at high latitude, J. Atmos. Terr. Phys., 55, 697, 1993.

Ward, W. E., D. Y. Wang, B. H. Solheim, and G. G. Shepherd, Observations of the two-day wave in WINDII data during January 1993, Geophys. Res. Lett., 23, 2923, 1996.

Williams, C. R., and S. K. Avery, Diurnal nonmigrating tidal oscillations forced by deep convection, J. Geophys. Res., 101, 4079, 1996.

Williams, P., T. Virdi, G. Jones, and A. Huuskonen, A comparison of three methods of measuring tidal oscillations in the lower thermosphere, J. Atmos. Terr. Phys., 56, 1347, 1994.

Wu, D. L., P. B. Hays, W. R. Skinner, A. R. Marshall, M. D. Burrage, R. S. Lieberman, and D. A. Ortland, Observations of the quasi-2-day wave from the high-resolution Doppler imager on UARS, Geophys. Res. Lett., 20, 2853, 1993. 